\title{
Avaliação da Inserção do Brasil no Comércio Internacional por Intensidade Tecnológica por meio de Análise de Redes
}

\section{Evaluation of Insertion of Brazil on International Trade by Technological Intensity through Network Analysis}

\author{
Daniela Fernanda Yamane* \\ Danielle de Jesus Silva** \\ Graciele de Fátima Sousa* ** \\ Celio Hiratuka****
}

\begin{abstract}
Resumo: O presente artigo explora a inserção do Brasil no comércio mundial utilizando a metodologia de análise de redes. O principal objetivo do artigo é verificar a posição e a inserção do Brasil nas redes comerciais em diferentes grupos de produtos classificados por categorias tecnológicas e sua evolução entre 2003 e 2012. Para isso, são utilizadas medidas de centralidade e apresentada a posição do país em diferentes clusters de países de acordo com sua importância na rede mundial de comércio. Busca-se apresentar, de maneira pioneira, como uma metodologia que vem sendo crescentemente utilizada nas ciências sociais e também nos estudos econômicos de comércio internacional, podendo ser aplicada para o caso brasileiro de forma complementar aos indicadores e metodologias tradicionais.
\end{abstract}

Palavras-chave: Redes de comércio. Exportações. Brasil.

Abstract: The present paper explores the insertion of Brazil in world trade using network analysis methodology. The main purpose of the article was verify the position and the insertion of Brazil in the trade networks of different technological categories and its evolution from 2003 to 2012, using measures of centrality and presenting the country's position in different clusters of countries. At the same time, the paper aimed to demonstrate how a methodology that has been increasingly used in the social sciences, and also in economic studies of international trade, can be applied to the Brazilian case as a complementary tool to the traditional indicators and methodologies.

Keywords: Trade networks. Exports. Brazil.

JEL Classification: F10.

\footnotetext{
* Doutoranda em Economia pela Universidade Estadual de Campinas (Unicamp). E-mail: daniela yamane@yahoo.com.br

** Mestre em Economia pela Universidade Federal da Bahia (UFBA). E-mail: danielle_unes@ hotmail.com

*** Doutoranda em Economia pela Universidade Estadual de Campinas (Unicamp). Economista do Centro de Pesquisas Econômico-Sociais (Cepes) do Instituto de Economia da Universidade Federal de Uberlândia (UFU). graciele.sousa@yahoo.com.br

* *** Doutor em Economia pela Universidade Estadual de Campinas (Unicamp). Professor do Instituto de Economia da Unicamp. E-mail: celiohiratuka@gmail.com
} 


\section{1 lntrodução}

O comércio mundial é caracterizado por uma rede complexa de trocas, envolvendo interações entre dois ou mais agentes residentes em países diferentes. Apesar disso, a maioria dos estudos sobre comércio internacional considera as relações entre os países de maneira isolada, não incorporando sua dimensão estrutural. Ou seja, os trabalhos tradicionais analisam o país $x$ e o país $y$ no comércio internacional de algum bem ou serviço, mas não exploram a relação entre eles e o efeito que a ligação de $x$ e/ou de $y$ com um terceiro país $z$ exerce sobre eles e sobre os demais países em um sistema complexo de trocas (BENEDICTIS et al., 2013).

As metodologias mais sofisticadas que buscam incorporar a dimensão estrutural das relações entre os países se voltam para técnicas de equilíbrio geral para simular os efeitos do comércio sobre os países. Nessas metodologias, é necessário especificar todas as relações econômicas para prever mudanças nas variáveis de interesse como preço, produto e bem-estar econômico, sendo também muito sensíveis às mudanças nos parâmetros utilizados para as previsões. ${ }^{1}$

A utilização da análise de redes, por outro lado, permite incorporar essa dimensão estrutrual das relações comerciais internacionais sem recorrer a hipóteses simplificadoras e, ao mesmo tempo, aproveitando a riqueza de informações permitida pela crescente disponibilidade de dados de comércio desagregados por produtos e por países. Desse modo, incluindo na análise as relações comerciais, tem-se uma visão estrutural desse comércio, considerando a dependência de um país em relação aos demais e considerando as relações comerciais estruturadas em forma de rede. Dessa forma, a análise de redes possibilita olhar a interdependência e os efeitos das relações na estrutura da rede de trocas mundiais.

Partindo dos avanços possibilitados pela incorporação da análise de redes sobre os dados de comércio, este artigo busca analisar a inserção do Brasil nos fluxos globais de exportação. Busca-se responder ao seguinte questionamento: qual foi a inserção do Brasil na rede de comércio internacional considerando os grupos de produtos por intensidade tecnológica em 2003 e 2012?

Além desse objetivo principal, pode-se destacar também a busca por mostrar os resultados da utilização de análise de redes para o comércio internacional do Brasil, o que pode resultar em uma agenda de pesquisa futura bastante promissora, uma vez que é uma metodologia ainda pouco utilizada no caso brasileiro, apesar de no cenário internacional ser crescentemente aplicada em diversas ciências sociais, inclusive na área de economia. Finalmente, este artigo também é relevante em razão do debate sobre o perfil de inserção comercial do Brasil, no qual vários autores têm ressaltado a reprimarização da pauta comercial, associando-a

$1 \quad$ Ver, por exemplo, Hertel et al. (1997) que aborda o modelo global trade analisys project (GTAP) de equilíbrio geral computável. Disponível em: <https://www.gtap.agecon.purdue.edu>. 
a um processo de desindustrialização. Embora não seja o objetivo principal, as informações aqui apresentadas podem contribuir para esse debate.

O artigo está estruturado em três seções, além desta introdução: na seção 2 realiza-se uma breve recuperação dos principais elementos da literatura de comércio mundial e aprofunda-se a discussão da análise de redes e da metodologia a ser adotada neste trabalho; na seção 3 apresenta-se uma breve contextualização sobre a inserção brasileira nas exportações globais utilizando indicadores tradicionais de comércio internacional; em seguida, mostram-se os resultados da aplicação da metodologia de redes para analisar a inserção do Brasil; a partir dos indicadores de centralidade de rede, são apresentadas as diferenças setoriais dentro da rede global de comércio por intensidade tecnológica e a inserção do Brasil em cada rede, além de uma análise de cluster para verificar o posicionamento do país; por fim, na quarta seção traçam-se as considerações finais deste estudo.

\section{Análise de Redes e Comércio Internacional: Revisão da Literatura e As- pectos Metodológicos}

A presente seção visa abordar de maneira sucinta a discussão conceitual da metodologia escolhida neste estudo, a partir da literatura teórico-metodológica sobre análise de redes e sua relação com as pesquisas de comércio internacional. Em seguida, apresenta-se a estratégia empírica utilizada no desenvolvimento do trabalho ao abordar o banco de dados, a taxonomia da classificação dos produtos por intensidade tecnológica e a metodologia das medidas/indicadores de análise de redes que estão presentes na pesquisa e que propiciam o alcance do objetivo central proposto.

\subsection{Uma Visão Geral sobre Comércio e Análise de Redes}

A análise de redes tem as suas origens na sociologia e se desenvolveu por possibilitar a análise de dados relacionais e a modelagem de estruturas resultantes da interação entre agentes inseridos em sistemas complexos. Assim, por se tratar de um conjunto de instrumentais flexíveis e, ao mesmo tempo, formais, a análise de redes vem sendo amplamente utilizada nas mais diversas áreas (SCOTT, 2000). Sua ênfase na interação entre os agentes permite colocar a dimensão estrutural e a propagação de efeitos no centro da análise, pois a relação entre dois agentes $i$ e $j$ não é considerada de forma isolada e independente da relação entre $j$ e $k$ e da relação entre $i$ e $k$. As redes representam uma teia de relações (sejam sociais e/ou econômicas) entre os agentes, desempenhando um papel central na análise e transmissão de informações (JACKSON, 2010). Dessa maneira, espera-se que informações adicionais possam ser extraídas a partir dessa estrutura dinâmica, as 
quais não seriam passíveis de análise ao olhar apenas para os indivíduos e suas respectivas características de forma independente.

O modelo de rede de comércio mundial a ser tratado neste trabalho, seguindo a definição de Dueñas e Fagiolo (2013), é definido como a rede que representa, em cada ano, a teia de relações comerciais bilaterais entre os países do mundo, sendo que tal método propicia ferramentas poderosas para descrever formalmente e testar teorias de sistemas de interação complexas (SMITH; WHITE, 1992).

A importância da utilização de análise de redes para o comércio mundial está relacionada ao fato de que o comércio é um importante canal de interação entre os países e que a análise tradicional das estatísticas das relações comerciais pode não conseguir capturar o impacto indireto que uma economia exerce sobre o comércio de outras economias (DUEÑAS; FAGIOLO, 2013). Assim, a aplicação da metodologia de rede permite considerar os vínculos indiretos das relações comerciais, bem como verificar a posição de cada país na rede, sendo que essa posição tem implicações para o crescimento dos países e permite entender a evolução da integração econômica.

Os trabalhos pioneiros que utilizaram a análise de rede com dados de comércio internacional estavam mais atrelados à teoria do sistema-mundo, desenvolvida por Wallerstein (1974), e buscavam encontrar padrões nos dados de comércio que permitissem classificar os países de acordo com sua posição em países do centro, da periferia ou da semiperiferia (SNYDER; KICK, 1979), assim como a evolução dos países e a dinâmica de mudanças entre os estratos ao longo do tempo (SMITH; WHITE, 1992).

Mais recentemente, alguns estudos têm se preocupado em fundamentar as propriedades topológicas e a dinâmica das redes de comércio internacional, como, por exemplo, os de Serrano et al. (2007) e Fagiolo, Reyes e Schiavo (2009). ${ }^{2}$ Esses autores apresentam as propriedades estatísticas da teia de relações de importação e exportação entre os países (utilizando uma abordagem ponderada de redes), o que permitiu proporcionar um maior detalhamento de suas estruturas topológicas, destacando as limitações dos indicadores padrão de comércio internacional, representados apenas pelas ligações diretas no que tange ao comércio bilateral.

A avaliação de redes permite uma visão da integração dos países no comércio diferente das medidas de abertura comercial padrão, como, por exemplo, a de comércio total sobre o PIB. A vantagem dos indicadores de rede relaciona-se à ca-

2 Fagiolo, Reyes e Schiavo (2009), com auxílio da metodologia de análise de redes, e utilizando dados de comércio internacional, construíram redes ponderadas direcionadas, compostas por 159 países, no período de 1981 a 2000, com o objetivo de avaliar a fração de ligações iguais a zero, num determinado ano $t$, e aquelas que se tornaram positivas em $t+\sigma$, sendo $\sigma=1,2, \ldots$, e o percentual de ligações estritamente positivo em $t$ que desapareceram no ano $t+\sigma$. Isso permite observar as relações comerciais que surgiram ou se extinguiram durante o período de análise. 
pacidade de extrapolar as relações de primeiro grau e de capturar toda a estrutura de relações da rede de comércio, aprofundando, assim, a análise da integração entre os países.

Reyes, Schiavo e Fagiolo (2007), por exemplo, utilizam a análise de rede para avaliar a estrutura das relações comerciais internacionais e a posição na rede dos países asiáticos (Tailândia, Filipinas, Malásia, Coreia, Indonésia e China) e latino-americanos (Venezuela, México, Chile, Brasil e Argentina) no período de 1980 a 2005. Os indicadores de rede utilizados no trabalho são, para avaliar a conectividade de primeiro grau, o node degree, o node strenght e o node disparity, e as medidas de conectividade de grau mais elevado são a de clustering e a random-walk betweenness. ${ }^{3}$

Reyes, Schiavo e Fagiolo (2007) apontam que os resultados, a partir de indicadores tradicionais, mostram que a abertura comercial foi crescente nas duas regiões. Entretanto, os indicadores de rede apresentaram uma diferença representativa no grau de integração e na dinâmica das duas regiões. Os países asiáticos apresentaram uma maior integração na rede de comércio internacional e se moveram da periferia da rede de comércio para o núcleo. Essa região esteve envolvida em relações comerciais mais intensas que a América Latina e essa maior integração aumentou as exportações e trouxe benefícios para a concorrência e o transbordamento de conhecimento. Por outro lado, a América Latina permaneceu estagnada na rede. Dessa forma, a rede de comércio internacional exibiu uma configuração de marginalização de alguns países, não permitindo que explorassem todos os ganhos do comércio. Assim, o posicionamento do país na rede é fundamental, contrapondo-se às análises que consideram apenas o grau de abertura econômica.

Além disso, a abordagem ponderada de redes de comércio internacional tem mostrado que os países integrantes que possuem muitos parceiros comerciais e/ou possuem relações comerciais de grande intensidade são também aqueles globalmente centrais e mais ricos. Em geral, o comércio realizado entre muitos parceiros, levando em consideração, também, a intensidade das relações, pode formar alguns aglomerados de comércio internacional (FAGIOLO; REYE; SCHIAVO, 2009).

3 Random-walk betweenness é uma medida de centralidade de nó que capta os efeitos da magnitude das relações que tem um nó com outros nós da rede, bem como o grau/força do nó em questão. Para essa medida, Newman (2005 apud REYES; SCHIAVO; FAGIOLO, 2007) assume que um nó de origem envia uma mensagem para um nó de destino: a mensagem é transmitida inicialmente a um nó vizinho e, em seguida, a mensagem seguinte forma uma ligação de saída a partir desse vértice, escolhido aleatoriamente, e continua de uma forma semelhante até que ele atinja o nó de destino. A medida de centralidade random-walk betweenness explora aleatoriamente toda a extensão das cadeias comerciais presentes na rede para o país i e considera a análise de parceiros além dos parceiros comerciais de um ou dois graus de separação do país $i$. 
Dessa forma, a rede de relacionamentos de importação-exportação entre os países fornece recursos importantes na compreensão e explicação de questões de comércio internacional, como a globalização econômica e a internacionalização, podendo ajudar no esclarecimento de como as políticas econômicas afetam os mercados internacionais e de como os choques econômicos são transmitidos entre países (FAGIOLO; REYE; SCHIAVO, 2009).

É importante destacar também que alguns estudos mais recentes têm buscado avançar no sentido de incorporar a possível heterogeneidade existente entre os diferentes produtos transacionados. Mahutga (2006), por exemplo, retomando a tradição de análise sistema-mundo, associa a estrutura da rede de comércio internacional à localização de países individualmente dentro dessa estrutura que poderia determinar seu acesso aos mercados e parceiros comerciais, bem como a um nível de sofisticação industrial, medida pelas categorias de produtos exportados. O referido autor classificou os produtos da Standard International Trade Classification (SITC), revisão um a dois dígitos, em quatro grupos: alta tecnologia/manufaturas pesadas; extrativo; baixos salários/manufaturas leves; produtos alimentícios. A rede foi composta a partir de 53 países e o estudo realizado entre os anos de 1965 e 2000. O método de investigação envolveu o conceito de rede de equivalência regular, que localiza atores que se relacionam com outros atores em uma rede de uma mesma maneira. Os resultados fornecem evidências robustas de que a economia mundial continua a operar dentro dos limites de uma estrutura hierárquica centro/periferia, além de sugerir que os níveis desiguais de processamento continuam a criar desigualdade estrutural por meio da reprodução de uma divisão internacional do trabalho segmentada. Existe, ainda, um elevado grau de estabilidade estrutural, observado nas décadas mais recentes, embora alguns países como Coreia do Sul, Cingapura e Turquia tenham demonstrado mobilidade ascendente significativa.

O estudo de Barigozzi et al. (2010), por outro lado, analisa as redes de comércio de maneira desagregada para as 97 posições do sistema harmonizado a dois dígitos para 162 países entre 1992 e 2003 . Os resultados do trabalho mostram que as estruturas das redes particulares para os produtos desagregados são bastante heterogêneas entre si, indicando níveis de centralidade e conectividade bastante diferentes dos observados para as relações de comércio tomadas em nível agregado. Além disso, o resultado agregado, que aparece como uma rede fortemente conectada, na verdade é resultado de um grupo de países que é fortemente conectado em todos os produtos, enquanto existem países que ocupam uma posição não tão central, mas que se conectam de maneira fraca em apenas alguns produtos. Esse resultado ressalta a importância de se trabalhar em um nível de análise mais desagregado e não considerar os fluxos totais para estabelecer a rede e a interação entre os países. 
Finalmente vale destacar que embora no cenário internacional as propriedades estatísticas desse modelo estejam sendo bastante estudadas, recebendo várias contribuições nos últimos anos e mostrando que essa abordagem metodológica traz elementos essenciais para entender a posição de um país no comércio mundial, no cenário brasileiro de pesquisas, o modelo de análise de redes ainda é pouco difundido. Na pesquisa bibliográfica realizada para este artigo foi encontrado apenas o texto de Lautenschlager e Catermol (2014) que se concentra em apresentar indicadores de centralidade de rede para os fluxos agregados de comércio em nível mundial e regional entre 1960 e 2000.

\subsection{Aspectos Metodológicos: Base de Dados e Medidas de Centralidade}

A metodologia utilizada neste trabalho foi desenvolvida de modo a permitir apreender a posição do Brasil na rede de comércio internacional por intensidade tecnológica nos anos de 2003 e 2012.

Os dados secundários utilizados no trabalho são referentes às exportações ${ }^{4}$ (2003 e 2012), disponibilizados no site oficial da Base pour l'Analyse du Commerce International (BACI), do Centre d'Etudes Prospectives d'Informations Internationales (CEPII). Esses dados de exportações fornecidos pela BACI-CEPII para 218 países, para 2003, e 220 países, para 2012, classificados de acordo o sistema harmonizado (HS) a seis dígitos, foram transformados para o sistema SITC-Revisão 3 a três dígitos ${ }^{5}$ e reagrupados de acordo com a classificação de intensidade tecnológica proposta por Lall (2000) (ver Quadro 1).

$4 \quad$ Ressalta-se que foi realizado um corte inicial, em que o trabalho utilizou os dados referentes aos 90\% do comércio total, sendo excluídos os fluxos menos significativos. Esse corte foi necessário para uma melhor representação das redes.

5 Para realizar a transformação da classificação HS para SITC foi utilizada a tabela de correlação desenvolvida pela United Nations Statistics Division, disponível em: < http://unstats.un.org/unsd/ trade/hs2_2sitc3.htm > . A partir dessa transformação foi possível agrupar os setores a três dígitos do sistemā SITC - revisão 3. 


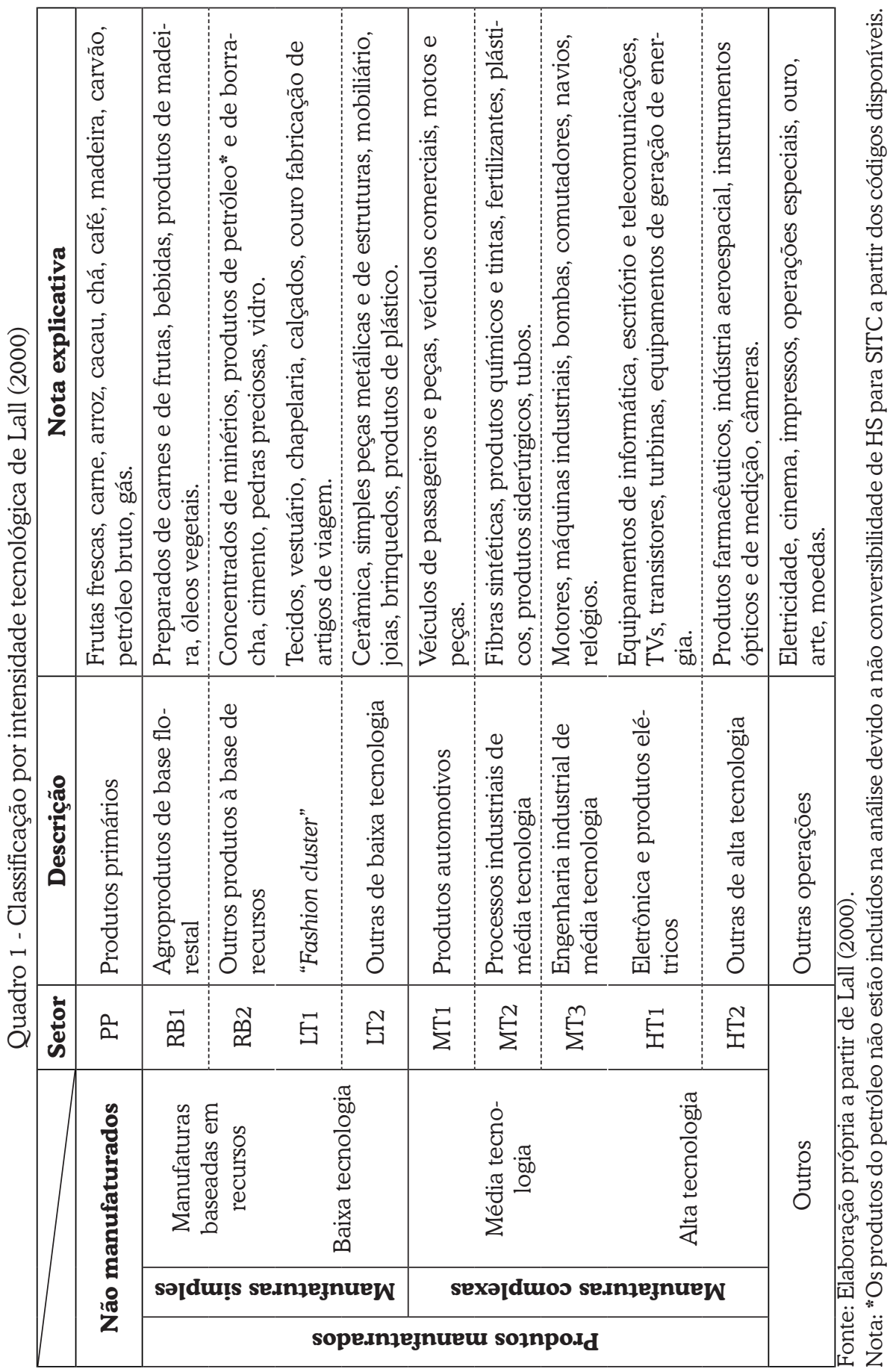


A metodologia de classificação por intensidade tecnológica de Lall (2000) é uma boa aproximação para medir o grau de inserção econômica dos países que compõem uma determinada rede de comércio, observando o grau de sofisticação dos produtos exportados. Vale destacar que o nível de intensidade tecnológica também pode ser medido por meio da complexidade atingida pelos países, em função da incorporação de conhecimento ao processo produtivo, tal como proposto por Hausmann e Hidalgo (2009). A complexidade de uma economia está relacionada à multiplicidade de conhecimentos incorporada e, nesse contexto, é tida como uma expressão da capacidade dos indivíduos de executarem determinadas funções. A metodologia criada por Hausmann e Hidalgo (2009) associa a complexidade de uma economia a dois conceitos: diversidade e ubiquidade. A diversidade diz respeito ao número de países que têm capacidade de produzir determinados produtos, enquanto a diversidade está associada ao número de produtos que um país tem capacidade de exportar. Países ricos em geral têm uma pauta diversificada e exportam produtos pouco ubíquos, enquanto países de menor renda são mais especializados e exportam produtos mais ubíquos. Partindo dessa ideia, Hausmann et al. (2011) propõem, em seu The Atlas of Economic Complexity, que a riqueza observada nas nações é impulsionada pelo conhecimento incorporado à produção, a partir da análise da pauta exportadora de um determinado país. No entanto, tal método remete a uma aproximação inicial de identificação dos determinantes do nível de complexidade dos países, pois, quando se observa produtos como, por exemplo, o nióbio, que é pouco ubíquo em função de sua raridade e não à sua complexidade, estes não atenderiam aos resultados esperados dos índices. Além disso, textos recentes, como os de Tacchella et al. (2013) e Zacaria et al. (2014) têm questionado a metodologia utilizada por Hausmann e Hidalgo (2009), o que revela que existem questões ainda em debate sobre a sua utilização.

É importante ressaltar também que a utilização da classificação por intensidade tecnológica desenvolvida por Lall (2000) justifica-se por ser uma classificação que permite, em suas subdivisões, realizar uma aproximação bastante interessante com características dos setores em termos de estruturas de mercado e padrões de progresso técnico, possibilitando uma análise em conjunto com estudos setoriais.

Em seguida foram elaboradas as redes de relações comerciais para cada setor, estimadas as medidas de centralidade de grau de saída não ponderado, de grau de saída ponderado e de autovetor de saída ponderado ${ }^{6}$ para todos os países pertencentes às redes (com foco nos resultados do Brasil) e uma análise de cluster, a fim de identificar a organização hierárquica dos grupos de países que compõem as redes.

6 As redes e as medidas de centralidades foram elaboradas no software Pajek. Para mais conhecimento, ver Nooy, Mrvar e Batagelj (2005). 
As medidas de centralidade são indicadores absolutos de tal modo que estes não podem ser utilizados para comparar centralidades de redes com diferentes tamanhos. Então, é preciso que essas medidas sejam normalizadas ${ }^{7}$ a fim de se obter valores de zero a um (do menor ao maior valor possível). Assim, os indicadores normalizados são chamados de medidas relativas (BENEDICTIS et al., 2013).

A medida de centralidade de grau de saída não ponderado envolve a quantidade de ligações que um vértice (país) possui e é dada pela seguinte equação (BENEDICTIS et al., 2013):

$$
\text { Centralidade de grau de saída não ponderado: } C_{D_{o u t}}^{N}=\frac{\sum_{j \neq i}^{N} \mathcal{L}_{i j}}{(N-1)},
$$

sendo que $N$ é o número total de países incluídos na análise e $\mathcal{L}_{i j}$ é o elemento (i,j) na matriz de adjacência do comércio, em que $i$ é o indicador da linha correspondente aos países exportadores e $\mathrm{j}$ é a coluna correspondente aos países importadores. Se $\mathcal{L}_{i j}=1$, então os dois países i e j são parceiros. Se $\mathcal{L}_{i j}=0$, então $i$ e j não são parceiros comerciais. No caso de grau de saída, $\sum_{j \neq i}^{N} \mathcal{L}_{i j}$ representa o número total de países para o qual o país i é exportador. Normalizando por $N$-1, o indicador irá de zero a um, e quanto mais próximo de um, maior a conexão do país com o resto da rede (BENEDICTIS et al., 2013).

Desse modo, a análise da medida de centralidade local, de grau de saída não ponderado, mede quanto um país está conectado com os demais países, ou seja, o número de arcos (ligações) que saem de um país (BENEDICTIS et al., 2013). Quanto maior o número de vizinhos conectados, maior a influência e o controle sobre os demais países da rede de comércio de cada setor.

O termo "não ponderado" significa que essa medida não está ponderada pelo valor exportado de cada país. Sendo assim, estimou-se a medida de centralidade de grau de saída ponderado, que é dimensionada pela saída de arcos ponderados pelo volume de comércio de exportações, ou seja, examina a centralidade tendo como peso o volume exportado em vez de parceiros comerciais (BENEDICTIS et al., 2013):

$$
\text { Centralidade de grau de saída ponderado: } C_{S_{\text {out }}}^{N}=\frac{\sum_{j \neq i}^{N} W_{i j}}{(N-1)},
$$

sendo que $W_{i, j}$ é o volume de exportação de uma ligação entre dois países i e j e as demais variáveis têm a mesma definição da fórmula centralidade de grau de saída não ponderado.

A terceira medida estimada neste trabalho foi a centralidade de autovetor, que é uma medida global e que enfatiza a importância dos vértices, não apenas

$7 \quad$ Para normalizar os valores das medidas de centralidade, divide-se o valor do indicador por ( $N-1)$, sendo $N$ o número de vértices (países). 
dos países, mas também dos seus vizinhos. Ou seja, associa a centralidade de um país com as características de seus parceiros comerciais, como quão importantes, centrais, influentes ou bem agrupados são eles. Não é indiferente um país estar conectado a outros países centrais ou periféricos. Assim, não é somente a própria centralidade que importa para essa medida, mas também a centralidade dos vizinhos. Valores maiores indicam que o vértice está ligado a muitos outros, que, por sua vez, também estão ligados a muitos outros, ou seja, ligados a países que são mais importantes e apresentam posições mais centrais. Assim, o país estará em uma sub-rede maior, mais densa e coesa (BENEDICTIS et al., 2013).

A medida de autovetor é a centralidade de um vértice $i$ adicionando-se a centralidade dos outros vértices a que ele se conecta. Ou seja, a centralidade do vértice i será a combinação linear das centralidades dos vértices que se conectam a i. Assim, nessa medida é possível capturar as influências diretas e indiretas.

Neste trabalho foi estimada a centralidade de autovetor de saída ponderado, ${ }^{8}$ a fim de se medir o papel central do país $i$ (país exportador), como a soma das centralidades dos autovetores dos seus vizinhos ponderado pelo volume de comércio (BENEDICTIS et al., 2013) a partir da solução de uma matriz binária:

$$
C_{\text {Eout }}(\mathrm{i})=\mathrm{W}_{\mathrm{i} 1} C_{E}(1)+\mathrm{W}_{\mathrm{i} 2} C_{E}(2)+\ldots+\mathrm{W}_{\mathrm{i}(\mathrm{N}-\mathrm{l})} C_{E(\mathbb{N}-1)}+\mathrm{W}_{\mathrm{iN}} C_{E}(\mathrm{~N})
$$

O sistema de equações, incluindo a centralidade de autovetor de todos os países $(N)$, pode ser apresentado na seguinte forma matricial:

$$
(I-W) \vec{C}_{\text {Eout }}=0
$$

em que I é a matriz identidade e $\vec{C}_{\text {Eout }}$ é o vetor N x 1 de centralidades dos autovetores dos países (i). A matriz de adjacência medida está ponderada pelo volume de exportação de uma ligação entre dois países (W).

A análise de cluster foi realizada no software Pajek e utiliza como critério o índice de dissimilaridade, um algoritmo para criar partições e agrupar os países menos dissimilares. De acordo com Nooy, Mrvar e Batagelj (2005), esse índice não considera o valor dos vetores, mas sim o perfil das ligações, podendo variar de zero a um, sendo que zero representa que os vértices são completamente semelhantes. Por outro lado, quanto mais próximo de um, mais diferentes os países serão. Destaca-se que, para o agrupamento dos clusters, tanto as relações externas ao bloco, quanto as relações internas são importantes. Para o cálculo do índice de dissimilaridade utilizaram-se como especificações "d1"9 e "output" (saída). O tipo

8 Para a estimação dessa medida, utilizou-se um software econométrico - Stata.

$9 d_{1}(u, v)=\left|N_{u}+N_{v}\right| / 1$ st maxdegree+2nd maxdegree, em que $u$ e $v$ são os vértices, $N_{u}$ é um conjunto de saída de arcos de $u$ e $N_{v}$ é um conjunto de saída de $\operatorname{arcos}$ de $v$, dividido pelo primeiro maior grau e segundo maior grau na rede. 
de equivalência é a estrutural, que se baseia na similaridade ou dissimilaridade entre os vértices no que se refere ao perfil das linhas e colunas na matriz de adjacência. Entretanto, no comércio internacional dificilmente há países com ligações idênticas, de forma que esse método detectará clusters de vértices que são equivalentes quase estruturais, ou seja, os menos dissimilares.

O programa permite escolher o número de clusters que se deseja dividir a rede. Esse número, por sua vez, dependerá das características e da estrutura da rede que se está trabalhando. No caso deste estudo, optou-se por dividir em quatro clusters para se verificar a posição dos países: cluster 1, cluster 2, cluster 3 e cluster 4 . O cluster 1 está no núcleo, enquanto que os demais clusters estão em posição crescentemente periférica na rede. O cluster 1 apresentará relações intensas tanto com os países do núcleo, quanto com os países da periferia, enquanto que os países dos demais clusters apresentarão poucas ligações entre eles e mais com os países do cluster 1.

\section{Análise dos Resultados para o Brasil}

Com o objetivo de analisar a posição e a inserção do Brasil nas redes comerciais em diferentes grupos de produtos classificados por categorias tecnológicas em 2003 e 2012, a partir da utilização da metodologia posta anteriormente, os principais resultados encontrados nesta pesquisa estão detalhados nas próximas quatro subseções.

\subsection{Contextualização e Análise de Indicadores Tradicionais de Comércio Internacio- nal por Intensidade Tecnológica para o Brasil}

Antes de analisar os indicadores sobre a inserção brasileira no comércio global baseada na metodologia de análise de redes, cabe tecer alguns breves comentários, de maneira a contextualizar a análise a ser realizada nas próximas subseções.

Se nas décadas finais do século XX o que marcou o crescimento do comércio global foi a tendência ao aumento dos fluxos comerciais decorrente da integração das cadeias produtivas em razão das estratégias empresariais de fragmentar suas atividades produtivas e aproveitar de maneira mais efetiva diferenciais de custos e especializações dos países,$^{10}$ no início do século XXI o fator mais marcante foi a forte elevação dos preços das commodities no mercado mundial.

Esse fato está associado aos impactos do forte crescimento da economia chinesa sobre a economia global nos anos 2000. É importante ressaltar que a econo-

10 Ver, por exemplo, Bair (2008), Baldwin (2012) e Elms e Low (2013). 
mia chinesa soube aproveitar o movimento de deslocamento de atividades manufatureiras ocorrido ao longo dos anos 1980 e 1990 para alavancar suas exportações e seu processo de desenvolvimento industrial, inicialmente com as etapas mais simples do processo de montagem dentro das cadeias das multinacionais, mas avançando rapidamente para etapas mais complexas das cadeias produtivas internacionais e com participação crescente de empresas nacionais privadas e estatais (SILVA; DATHEIN, 2014).

Mas o impacto sobre o preço das commodities está relacionado ao fato de que, como destacado por Medeiros (2013), a partir do início do século XXI, já não se pode atribuir o dinamismo chinês apenas à inserção nas indústrias exportadoras organizadas dentro das cadeias globais de valor, mas principalmente aos investimentos em infraestrutura, em especial a infraestrutura urbana, fato que passou a exercer forte impacto sobre a demanda de commodities e sobre a produção da indústria pesada.

O acelerado crescimento da infraestrutura urbana, com a consequente alteração nos padrões de consumo, somado à continuidade da expansão industrial explicam o forte impacto sobre a demanda e os preços das commodities minerais, metálicas, alimentícias e energéticas observadas a partir do início dos 2000. No entanto, embora tenham surgidos novos vetores de dinamismo, a inserção nas várias atividades manufatureiras voltadas para a exportação não foi abandonada, como mostra o crescente market share mundial da China em diferentes produtos e setores e seus efeitos sobre diferentes países e regiões (JENKINS, 2008).

É importante destacar que o crescimento sincronizado da economia global entre 2003 e 2008, assim como a liquidez exacerbada observada no período alavancando movimentos de especulação financeira com as commodities também tiveram influência e podem refluir com a redução do crescimento chinês. Ao mesmo tempo, a redução da demanda global no cenário pós-crise pode acentuar a competição por produtos manufaturados (HIRATUKA; SARTI, 2015).

Observando os impactos sobre os fluxos de comércio, é possível perceber como, entre 2003 e 2008, o crescimento médio do valor das exportações foi muito acelerado, crescendo a $16,4 \%$ ao ano. O crescimento médio anual de produtos agrícolas foi de $14,5 \%$, o de combustíveis e minerais de $29,4 \%$ e o de manufaturados $13,7 \%$. Por outro lado, o período pós-crise apresentou taxas de crescimento significativamente menores, mostrando a intensidade dos efeitos da crise global sobre os fluxos de comércio. Depois de forte queda em 2009, e de uma recuperação rápida em 2010, as exportações ficaram praticamente estagnadas em 2011 e 2012. Considerando o período 2008-2012, a taxa média de crescimento das exportações globais foi de apenas $3,4 \%$, sendo de $2,4 \%$ para os manufaturados, $4,0 \%$ para combustíveis e minerais e $5,2 \%$ para produtos agrícolas. 
Nesse contexto, é possível compreender melhor o debate travado no Brasil sobre o processo de reprimarização da pauta de exportações, assim como a intensa discussão sobre a existência de um processo de desindustrialização no Brasil e suas causas. Não é objetivo deste artigo retomar esse debate, mas simplesmente destacar alguns aspectos que apontam para questões importantes relacionadas à inserção externa e que devem guiar a análise dos indicadores apresentados na subseção seguinte. ${ }^{11}$

Cabe observar inicialmente que, depois de um longo esforço de expansão das exportações e de aumento da participação de manufaturados na pauta, ${ }^{12}$ nos anos 2000 o crescimento das exportações brasileiras esteve fortemente apoiado nas vendas de commodities agrícolas, minerais e metálicas. A referida expansão de preços e da quantidade global demandada em decorrência da expansão chinesa e do ciclo de crescimento da economia mundial impulsionou o aumento da participação brasileira nas exportações mundiais. De um patamar de 0,9\%, em 2003, o market share brasileiro atingiu 1,4\% em 2011, reduzindo-se um pouco em 2012, chegando a 1,3\%. A participação nas exportações de manufaturados, por outro lado, elevou-se apenas ligeiramente de 0,7\%, em 2003, para 0,8\% em 2006. No entanto, essa participação voltou a se reduzir, em 2009, para cerca de $0,7 \%$, se mantendo em torno desse patamar a partir de então até 2012.

Nesse cenário, a valorização cambial e o superávit em commodities têm sido apontados por diversos autores, como, por exemplo, Bresser-Pereira $(2008,2012)$ e Oreiro e Feijó (2011), como elementos explicativos para as dificuldades vivenciadas pela indústria brasileira. A disponibilidade de recursos, somadas à entrada de capitais ou às políticas cambiais populistas, voltadas para manter os salários reais artificialmente elevados, inviabilizariam a existência de indústrias competitivas que utilizam tecnologias no estado da arte mundial. Além disso, o perfil da estrutura produtiva acabaria revelando dificuldades de setores mais intensivos em tecnologia e conhecimento, que enfrentariam maiores problemas para concorrer com produtores internacionais. A expansão das exportações de commodities, portanto, seriam acompanhadas por mudanças na estrutura setorial da produção, com peso crescente de setores industriais menos complexos e com menor capacidade de efeitos de encadeamentos (FEIJÓ; LAMONICA, 2012; VERÍSSIMO et al. 2012). Essa situação acabaria também por se refletir no perfil de exportações, dada a dificuldade maior na inserção internacional dos setores mais sofisticados tecnologicamente e mais intensivos em conhecimento.

11 Ver Morceiro (2012) e Vergnhanini (2012) para sistematizações do debate.

12 As estatísticas históricas da Secex mostram que, em 1964, primeiro ano da série, as exportações de manufaturados representavam apenas $6,4 \%$ da pauta brasileira. Essa participação aumenta para 15,2\%, em 1970, e tem forte aumento ao longo da década, atingindo 44,8\% em 1980. O auge em termos de participação de manufaturados ocorre em 1993 (60,8\%), caindo a partir de então, em especial a partir dos anos 2000. 
Antes de se apresentar os indicadores baseados na metodologia de redes, pode ser interessante observar rapidamente alguns dos indicadores tradicionais de comércio internacional para o Brasil, tais como market share, participação na pauta comercial exportadora e vantagens comparativas reveladas. ${ }^{13} \mathrm{Com}$ isso, pode ficar mais evidente que a nova metodologia de análise de redes fornece elementos adicionais para a compreensão do posicionamento de um país no comércio mundial. A metodologia tradicional avalia o Brasil de forma isolada, diferente da que será desenvolvida nos próximos tópicos, que considera a dimensão estrutural das relações de toda a rede de comércio. Assim, ambas as abordagens se complementam e enriquecem a análise de comércio internacional, não sendo, portanto, excludentes.

O primeiro indicador da Tabela 1 aponta que o Brasil apresentou ganhos de market share principalmente nos setores de PP, RB1 e RB2. No entanto, é possível ver que houve um pequeno aumento de market share também em produtos manufaturados com maior grau de sofisticação, como MT1, MT2, MT3, HT2. Ou seja, por esse indicador, nos produtos manufaturados as perdas de market share teriam ocorrido somente nos produtos intensivos em trabalho (LT1 e LT2) e nos produtos HT1, associados ao complexo eletrônico. Dessa forma, apesar do aumento do peso na pauta exportadora dos produtos mais intensivos em recursos naturais, esse desempenho não parece corroborar a ideia de uma regressão na inserção exportadora, ou de um processo de desindustrialização que se observe a partir de dados de market share mundial.

13 Sendo: market-share $=X_{i k} / X_{k}$, em que $X_{i k}=$ exportações do produto $k$ pelo país $i$ e $X_{k}=$ exportações mundiais do produto $k$; pauta comercial exportadora = participação de cada setor, em porcentagem, na pauta comercial exportadora; e vantagens comparativas reveladas $=\left(X_{i k} / X\right) /\left(X_{k} / X\right)$, sendo $X_{i}=$ exportações totais do país $i, X=$ exportações mundiais totais e $X_{i k}$ e $X_{k}$ como definidas anteriormente. Para tornar o índice de VCR simétrico, foi realizado o seguinte procedimento: $(V C R-1) /(V C R+1)$, sendo assim os resultados do $V C R$ estarão entre $-1 \mathrm{e}+1$, sendo que os valores entre 0 e +1 representam vantagens comparativas e entre 0 e -1 desvantagens comparativas. 
Tabela 1 - Indicadores de comércio internacional tradicionais:

Brasil (2003 e 2012)

\begin{tabular}{c|cc|cc|cc}
\hline \multirow{2}{*}{$\begin{array}{c}\text { Setores/ } \\
\text { indicadores }\end{array}$} & \multicolumn{2}{|c|}{$\begin{array}{c}\text { Market share } \\
\text { (\%) }\end{array}$} & \multicolumn{2}{c|}{$\begin{array}{c}\text { Pauta comercial } \\
\text { exportadora } \\
\text { (\%) }\end{array}$} & \multicolumn{2}{c}{$\begin{array}{c}\text { Vantagens } \\
\text { comparativas } \\
\text { reveladas (VCR) }\end{array}$} \\
& $\mathbf{2 0 0 3}$ & $\mathbf{2 0 1 2}$ & $\mathbf{2 0 0 3}$ & $\mathbf{2 0 1 2}$ & $\mathbf{2 0 0 3}$ & $\mathbf{2 0 1 2}$ \\
\hline PP & 1,81 & 2,46 & 23,71 & 30,75 & 0,29 & 0,27 \\
RB1 & 2,76 & 3,76 & 19,14 & 16,69 & 0,47 & 0,45 \\
RB2 & 1,70 & 3,89 & 9,41 & 17,64 & 0,26 & 0,47 \\
LT1 & 0,88 & 0,54 & 5,69 & 1,88 & $-0,07$ & $-0,45$ \\
LT2 & 0,66 & 0,55 & 5,94 & 3,32 & $-0,21$ & $-0,44$ \\
MT1 & 0,84 & 0,97 & 7,80 & 4,89 & $-0,09$ & $-0,19$ \\
MT2 & 1,11 & 1,47 & 7,64 & 7,31 & 0,05 & 0,02 \\
MT3 & 0,61 & 0,74 & 8,90 & 7,11 & $-0,24$ & $-0,31$ \\
HT1 & 0,26 & 0,18 & 3,46 & 1,45 & $-0,59$ & $-0,77$ \\
HT2 & 0,55 & 0,69 & 3,99 & 3,33 & $-0,30$ & $-0,35$ \\
\hline
\end{tabular}

Fonte: Elaboração própria a partir de Centre D'etudes Prospectives D'informations Internationales (2015).

Quanto às vantagens comparativas reveladas, o país apresentou vantagens comparativas (valores positivos) nos três primeiros setores e em MT2, apesar deste último ser um valor reduzido e, em 2012, próximo de zero. Os demais setores exibiram desvantagens comparativas para os dois anos. É possível observar algumas indicações contraditórias quando se consideram os setores industriais de média e alta tecnologia. O setor MT1, por exemplo, apresenta ganho de market share, porém aumento no valor negativo do indicador de VCR. O mesmo acontece com o setor HT2. Já o setor MT2 teve ganho de market share e se manteve com VCR positivo, embora em patamar bastante próximo a zero.

Esta subseção buscou contextualizar de maneira breve o cenário das exportações mundiais e a inserção brasileira, destacando os indicadores tradicionais de comércio internacional. As próximas subseções serão baseadas no desenvolvimento da metodologia de análise de redes.

\subsection{Informações Gerais das Redes Comerciais por Intensidade Tecnológica}

A vantagem em representar o comércio internacional, por meio de uma rede de fluxos de comércio, é a possibilidade de visualizar o efeito da relação de negociação entre os países e da estrutura da própria rede, a qual revela padrões que são difíceis de serem observados em outras abordagens. 
Inicialmente, vale mencionar os aspectos gerais de cada rede de comércio por intensidade tecnológica nos anos de 2003 e 2012, a partir da Tabela 2. A análise representa o comércio internacional, englobando 90\% do comércio total de produtos primários (PP), de manufaturas baseadas em recursos (RB1 e RB2), de manufaturas de baixa tecnologia (LT1 e LT2), de média tecnologia (MT1, MT2 e MT3) e de alta tecnologia (HT1 e HT2) em 2003 e 2012.

Tabela 2 - Índices das redes de comércio por intensidade tecnológica $(2003 \text { e 2012) })^{14}$

\begin{tabular}{c|cc|cc|ccccccc}
\hline & \multicolumn{2}{|c|}{$\begin{array}{c}\text { No de } \\
\text { países }\end{array}$} & \multicolumn{2}{|c|}{$\mathbf{N}^{\circ}$ de arcos } & \multicolumn{2}{c}{ Densidade } & \multicolumn{3}{c}{ Grau médio } & \multicolumn{3}{c}{$\begin{array}{c}\text { Grau de } \\
\text { saída não } \\
\text { ponderado }\end{array}$} \\
& $\mathbf{2 0 0 3}$ & $\mathbf{2 0 1 2}$ & $\mathbf{2 0 0 3}$ & $\mathbf{2 0 1 2}$ & $\mathbf{2 0 0 3}$ & $\mathbf{2 0 1 2}$ & $\mathbf{2 0 0 3}$ & $\mathbf{2 0 1 2}$ & $\mathbf{2 0 0 3}$ & $\mathbf{2 0 1 2}$ \\
\hline PP & 158 & 151 & 1.842 & 1.726 & 0,074 & 0,076 & 23,32 & 22,86 & 0,412 & 0,366 \\
RB1 & 139 & 155 & 1.338 & 1.693 & 0,070 & 0,071 & 19,25 & 21,85 & 0,433 & 0,451 \\
RB2 & 113 & 123 & 1.067 & 1.112 & 0,084 & 0,074 & 18,88 & 18,08 & 0,419 & 0,479 \\
LT1 & 116 & 126 & 924 & 925 & 0,069 & 0,059 & 15,93 & 14,68 & 0,669 & 0,868 \\
LT2 & 106 & 130 & 933 & 1.088 & 0,084 & 0,065 & 17,60 & 16,74 & 0,463 & 0,786 \\
MT1 & 72 & 104 & 380 & 654 & 0,074 & 0,061 & 10,56 & 12,58 & 0,667 & 0,585 \\
MT2 & 116 & 129 & 1.147 & 1.407 & 0,086 & 0,085 & 19,78 & 21,81 & 0,483 & 0,638 \\
MT3 & 98 & 117 & 907 & 1.072 & 0,095 & 0,079 & 18,51 & 18,32 & 0,633 & 0,685 \\
HT1 & 59 & 79 & 539 & 601 & 0,158 & 0,098 & 18,27 & 15,22 & 0,647 & 0,810 \\
HT2 & 88 & 92 & 707 & 902 & 0,092 & 0,108 & 16,07 & 19,61 & 0,651 & 0,613 \\
\hline
\end{tabular}

Fonte: Elaboração própria a partir de Centre D'etudes Prospectives D’informations Internationales (2015).

Observa-se que as redes de setores não manufaturados e de manufaturas mais simples apresentaram um número maior de países participando dos fluxos comerciais, em ambos os anos. Destaque para a rede de comércio de PP, que teve o maior número de países participantes no ano de 2003 (158 países), e a rede de RB1 com 155 países em 2012. As redes de manufaturas mais complexas tiveram um número menor de países, sendo que o setor HT1 (associado ao complexo eletrônico) foi a rede que teve o menor número de países atuando nos anos de 2003 e 2012. Em seguida, aparecem o HT2 (no qual a farmacêutica e a aeroespacial são importantes) e o MT1 (complexo automotivo). Nestes setores, a entrada na rede parece ser mais difícil do que nos demais setores.

14 Os grafos das redes para cada setor para o ano de 2012 estão representados no Apêndice A, com os tamanhos dos vértices ponderados pela medida de centralidade grau de saída ponderado e a posição de acordo com a disposição geográfica. 
Mesmo assim, é importante destacar que todas as redes, com exceção da rede de PP, tiveram um aumento do número de países participantes. O maior aumento foi verificado na rede comercial de MT1, que apresentou um acréscimo de 44\%, de 2003 para 2012, sendo seguida pela rede de HT1, com um aumento de $34 \%$, e a rede de LT2 com um aumento de $23 \%$. As demais redes tiveram um aumento menor do que $20 \%$.

No que tange à relação entre os países nas redes, a Tabela 2 mostra que houve uma interação intensa entre os países em ambos os anos, especialmente nas redes dos setores de PP, RB1, MT2 e RB2, que em ambos os anos tiveram mais de mil ligações entre os países. Ressalta-se que a rede de PP foi a única que apresentou uma diminuição dos números de arcos de 1.842 arcos, em 2003, para 1.726 arcos em 2012. Enquanto isso, os demais setores tiveram um aumento na quantidade de ligações de 2003 para 2012, sendo que o maior acréscimo foi na rede comercial de MT1, na qual se observa um aumento de $72 \%$ do número de arcos existentes de 2003 a 2012, seguido pelo acréscimo de 28\% do número de ligações do grupo HT2. As redes que tiveram o menor número de ligações foram MT1, em 2003, e HT1 em 2012, contudo ambas as redes registraram mais ligações em 2012 do que em 2003.

Com relação às medidas de centralidade gerais das redes, observa-se que são caracterizadas pela alta dimensionalidade e forte heterogeneidade. Primeiramente, tem-se a densidade, ${ }^{15}$ que significa que, ao se tomar dois países de forma aleatória, a probabilidade de uma ligação de comércio existir entre esses países é dada pelo valor da densidade. Ou seja, tendo como exemplo o setor HT2, em 2003 a densidade da rede correspondia a 0,091, significando que, ao se tomar dois países aleatoriamente, a probabilidade de uma ligação comercial existir entre eles seria de 9,1\%, enquanto que, em 2012, com a densidade correspondendo a 0,107, a probabilidade de uma ligação entre dois países quaisquer seria de 10,7\%, mostrando que a rede se tornou mais densa. Em razão do aumento do número de participantes ter sido em geral maior do que o aumento do número de ligações, a maior parte dos setores apresentou redução nos indicadores de densidade. Apenas nas redes PP, RB1 e HT2 pode se verificar aumento entre 2003 a 2012.

A medida de densidade, no entanto, é afetada pelo seu tamanho (número de países pertencente a uma rede $-N$ ). Dessa forma, tal medida também não pode ser utilizada diretamente para fins de comparação entre redes de tamanhos diferentes. Por isso, a análise do grau médio ${ }^{16}$ apresenta-se como uma melhor alternativa, pois este elimina o efeito do tamanho da rede. Quanto maior o valor do grau médio, mais coesa é a rede.

\footnotetext{
15 Densidade $=\mathrm{m} /[\mathrm{N}(\mathrm{N}-1) / 2]$, em que $N$ é o número de países da rede e $m$, o número de ligações existentes. A densidade utilizada no trabalho equivale à densidade sem loops.

16 Grau médio $=p(N-1)$, sendo $p$ a probabilidade de ocorrência de uma aresta entre dois vértices (fixo, $m$ ).
} 
Assim, percebe-se que houve um aumento no grau médio das redes de comércio de RB1 (14\%), de MT1 (19\%), de MT2 (10\%) e de HT2 (22\%), indicando que, em 2012, a coesão estrutural dessas redes foi um pouco maior do que em 2003. Os demais setores analisados (PP, RB2, LT1, LT2, MT3 e HT1) apresentaram redes com uma menor coesão estrutural, quando se compara 2012 em relação a 2003, sendo que a maior queda foi registrada em HT1.

Fazendo-se uma comparação entre as redes, tem-se que o setor PP foi mais coeso do que as demais redes, tanto em 2003, quanto em 2012, mesmo tendo registrado uma diminuição da coesão de 2003 para 2012, enquanto que as redes menos coesas, em comparação com as demais, foram a MT1 e LT1.

A última informação da Tabela 2 envolve a medida de centralidade de grau de saída não ponderado geral, sendo que, quanto maior foi o seu valor, uma quantidade maior de países apresentou poder de centralidade na rede. É interessante notar que, entre 2003 e 2012, observa-se um movimento de aumento da heterogeneidade desse indicador entre os diferentes setores, em geral com os setores apresentando um aumento no grau de saída, isto é, com elevação do número de países apresentando poder de centralidade. Esse aumento foi mais evidente em LT1, LT2, MT2 e HT1. Apenas as redes de PP, MT1 e HT2 apresentaram uma diminuição dos seus valores do grau de saída não ponderado, significando que, em 2012, nessas redes um número menor de países estava tendo poder de centralidade em comparação ao que foi registrado em 2003.

Em resumo, os indicadores gerais sobre os fluxos de comércio globais mostram redes que em geral estiveram mais propícias à entrada de novos participantes. Além do aumento dos participantes, observou-se também uma tendência de aumento no número de ligações, reduções na densidade e coesão das redes e o aumento do número de países com grau de centralidade. Esse movimento provavelmente está refletindo a forte expansão do comércio observada entre 2003 e 2008 , ao mesmo tempo que os efeitos mais negativos decorrentes da crise global não devem ter sido totalmente capturados pela rede analisada em 2012, uma vez que 2009 foi um ano atípico de forte queda nos fluxos de comércio, 2010 foi um ano de recuperação e apenas em 2011 e 2012 se observou estagnação nos valores exportados. Cabe agora ver o posicionamento do Brasil nas redes.

\subsection{Brasil: Medidas de Centralidade e Posicionamento nas Redes}

A seguir, apresenta-se uma análise da rede para os diferentes produtos agrupados por intensidade tecnológica, destacando as medidas de centralidade de grau de saída não ponderado e ponderado e de autovetor de saída ponderado (ver Tabela 3). 


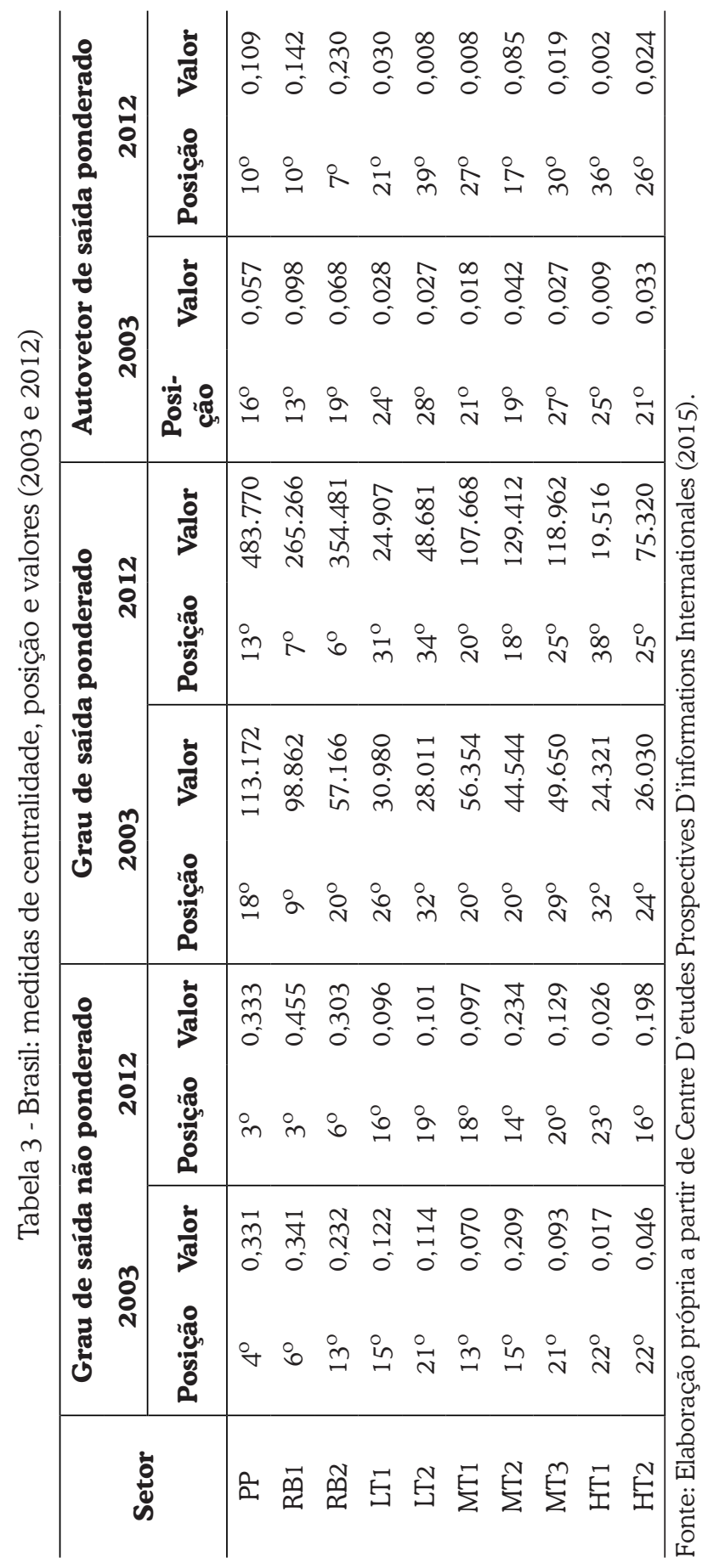


Considerando-se em primeiro lugar o grau de saída não ponderado, percebe-se que o país estava enviando fluxo de PP para 33\% dos países da rede, tanto em 2003, quanto em 2012, mostrando certa estabilidade no posicionamento (pequena queda da terceira para a quarta posição no ranking) na rede desses produtos. O segundo setor em que o Brasil esteve melhor posicionado foi o de RB1, no qual passou de sexto, em 2003, para terceiro em 2012. Ressalta-se que nesse setor o Brasil enviou fluxo para 34\% (em 2003) e 45\% (em 2012) dos países da rede.

Em RB2, a posição do Brasil também apresentou melhora com o aumento no número de parceiros comerciais, elevando o país da $13^{\mathrm{a}}$ para a $6^{\mathrm{a}}$ posição no ranking. Observa-se, assim, claramente um cenário no qual o Brasil aproveitou as oportunidades associadas à maior demanda por produtos associados às commodities, seja em sua forma primária (PP), seja com algum grau de processamento como na agroindústria (RB1) ou nas atividades associadas à indústria extrativa (RB2), para ampliar o número de parceiros comerciais.

Por outro lado, nos demais produtos manufaturados, a posição do Brasil não foi tão favorável. Os setores de LT1, MT1 e HT1, além disso, apresentaram piora de posição entre 2003 e 2012. Deve-se destacar o caso do setor MT1, que envolve principalmente o complexo automotivo. Era nesse setor que o Brasil apresentava melhor posição entre os produtos manufaturados mais complexos $\left(13^{\circ}\right.$ lugar $)$ em 2003. Apesar do indicador ter apresentado pequeno aumento em 2012, o Brasil passou a ocupar o $18^{\circ}$ lugar no ranking. Vale lembrar que, como visto na Tabela 2 , em termos gerais a evolução da rede de produtos MT1 teve um maior número de participantes, porém com maior coesão da rede e menor número de países apresentando centralidade. Nesse contexto, o Brasil não logrou manter sua posição, perdendo lugar para outros países.

Já nos setores LT2, MT2, MT3 e HT2, observou-se uma melhora de posição entre os dois períodos. Apenas no setor HT2 essa melhora foi significativa, com elevação da $22^{\mathrm{a}}$ para a $16^{\mathrm{a}}$ posição. Em grande medida, essa melhora está associada à indústria aeronáutica.

Essas informações do grau de saída não ponderado indicam que o Brasil é mais central nas redes de setores não manufaturados e de manufaturas mais simples, tendo uma maior inserção e influência nessas redes, enquanto tem um posicionamento e poder de influência menor nas redes comerciais de manufaturas complexas, especialmente de alta tecnologia. Tal fato demonstra a necessidade de o país buscar ampliar e diversificar suas conexões, principalmente nas redes dos setores que ainda apresentam baixo valor no indicador grau de saída não ponderado.

Os indicadores ponderados merecem um pouco mais de atenção na Tabela 3, uma vez que expressam a posição na rede considerando o valor das exportações, e não apenas o número de ligações. Uma primeira observação é que o 
indicador de grau de saída ponderado, em geral, coloca o Brasil em posição pior do que o grau de saída não ponderado. Ou seja, a inclusão das informações sobre o valor dos fluxos de saída mostra o país em pior situação do que quando se consideram somente as informações sobre as ligações.

Considerando-se as informações sobre o grau de saída ponderado para os diferentes setores, é possível confirmar a melhor situação relativa dos produtos mais básicos. A maior melhoria relativa ocorreu no setor RB2, com a passagem da posição $20^{a}$ para a posição $6^{a}$ no ranking entre 2003 e 2012. Nos PP e RB1, a posição relativa do Brasil aumentou de $18^{\circ}$ para $13^{\circ}$ e de $9^{\circ}$ para $7^{\circ}$ lugares, respectivamente, no mesmo período. Outros setores que apresentaram melhora de posição a partir desse indicador foram o MT2 e o MT3, embora, mesmo considerando a subida no ranking, a posição ainda possa ser considerada pouco satisfatória. O setor MT1, no qual se observou a pior evolução no indicador não ponderado, permaneceu estável na posição $20^{\mathrm{a}}$ considerando o indicador ponderado. Essa situação pode ser explicada pelo aumento do volume exportado, embora com um número reduzido de parceiros comerciais em relação aos demais participantes da rede. Já nos setores LT1, LT2, HT1 e HT2, a posição no ranking caiu entre os dois anos analisados.

Considerando-se agora a medida autovetor de saída ponderado, é possível confirmar novamente a melhora no posicionamento de commodities e baseados em recursos naturais ( $\mathrm{PP}, \mathrm{RB} 1, \mathrm{RB} 2$ ), indicando que, nessas redes, os países para os quais o Brasil exporta são, em sua maioria, países centrais nas redes comerciais. Os outros dois setores nos quais se observou uma melhora na posição do Brasil foram no LT1 e MT2. No caso do LT1, é interessante notar que, apesar da piora nos indicadores de grau de saída, a melhora no indicador de autovetor de saída ponderado mostra que o Brasil passou a se relacionar com países com maior grau de centralidade. No setor MT2, por outro lado, o sentido da mudança neste último indicador acompanhou o dos demais indicadores.

Enquanto isso, nas redes LT2, MT1, MT3, HT1 e HT2, o país piorou o seu posicionamento com base no autovetor de saída ponderado, mostrando que nessas redes de comércio de maior intensidade tecnológica os parceiros comerciais do Brasil não são tão centrais quanto nos setores de menor intensidade tecnológica. Assim, o Brasil tem menor centralidade de autovetor de saída ponderado e exerce menor influência nos setores de maior sofisticação tecnológica, se conectando com países menos centrais dentro da rede mundial.

A evolução dos diferentes setores ao longo do período, considerando os indicadores ponderados, pode ser visto de maneira sintética no Gráfico 1. Esse gráfico demonstra o posicionamento do Brasil no ranking, em cada rede de comércio por intensidade tecnológica, para as duas medidas de centralidade estimadas e o deslocamento dessas posições de 2003 para 2012. 
Gráfico 1 - Brasil: medida de centralidade local e global (2003 e 2012)

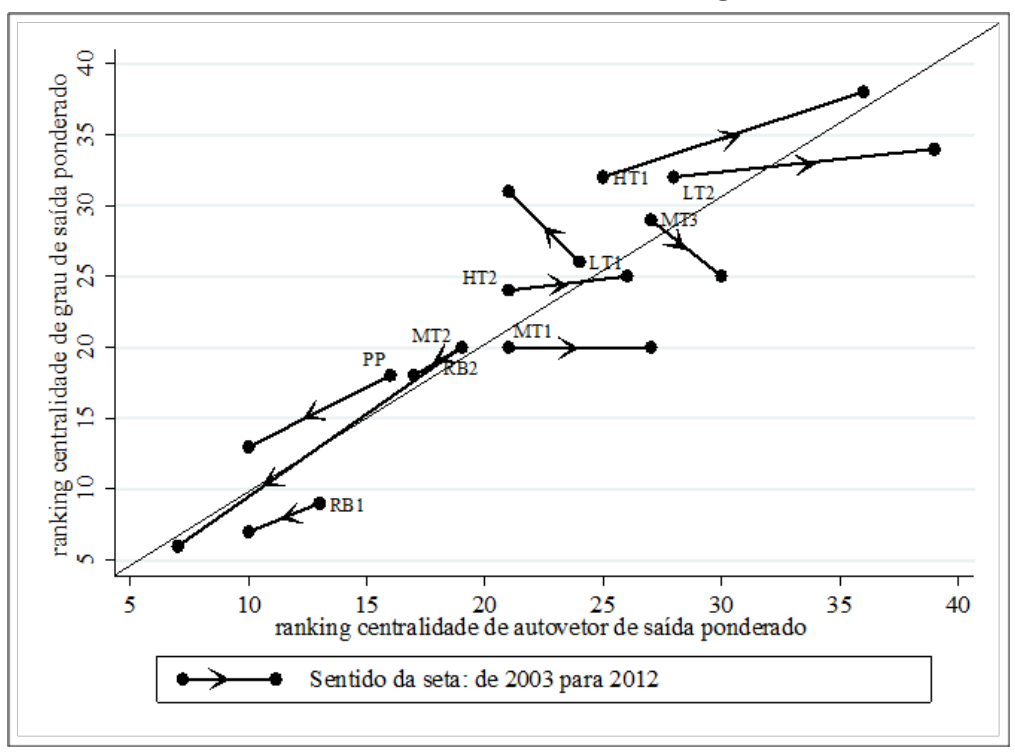

Fonte: Elaboração própria a partir de Centre D'etudes Prospectives D'informations Internationales (2015).

Quanto mais próximo da origem, melhor será a posição do Brasil no ranking, considerando os dois indicadores. Ao mesmo tempo, analisando as dispersões dos pontos em relação à linha da diagonal, quanto maior for a distância a partir dessa diagonal, maior a diferença no posicionamento relativo do setor expresso pelas duas posições. Os setores acima (abaixo) da linha diagonal são menos (mais) centrais para o Brasil, quando sua posição é medida por um indicador local em relação a uma medida global de centralidade. A evolução entre 2003 e 2012 pode ser medida, portanto, pela mudança de posição no gráfico. Uma alteração para mais perto da origem representa melhora nos rankings de centralidade.

A observação do Gráfico 1 permite identificar de maneira visual os quatro setores que tiveram uma melhora de posição relativa (PP, RB1, RB2 e MT2) nos dois rankings. Eram setores que já estavam mais perto da origem e que se moveram ainda mais no sentido da origem do gráfico. Também é possível observar que a alteração mais intensa foi no setor RB2, no qual se concentram produtos da indústria extrativa. O setor PP também teve deslocamento bastante intenso, enquanto nos setores RB1 e MT2 as mudanças foram um pouco menos intensas.

Nos grupos setoriais LT2, MT1, HT1, HT2, por outro lado, é clara a piora observada na inserção em razão do deslocamento para regiões mais distantes da origem no período considerado. Também é possível notar que nesses setores a pior inserção foi observada principalmente considerando o indicador global, ou 
seja, o perfil de parceiros comerciais passou a ser menos central em 2012 do que era em 2003. Finalmente, no caso dos setores LT1 e MT3, observou-se a melhora em um indicador e a piora em outro. No caso do LT1, houve melhora na posição do ranking de indicadores globais e piora no de indicadores locais, enquanto no MT3 observou-se o inverso.

A análise dos resultados demonstra que as exportações brasileiras, nos anos apresentados, estiveram fortemente sustentadas nas vendas de produtos primários agrícolas, minerais e metálicos. As tendências nos anos 2000 sinalizavam para esse fato, diante do cenário do comércio mundial marcado pela elevação dos preços das commodities associada à autonomia da economia chinesa no início da década. Por outro lado, nos setores de manufaturados não baseados em recursos naturais, a inserção brasileira apresentou em geral sinais de regressão, mostrando que não foram aproveitadas as oportunidades abertas dentro da rede global.

\subsection{O Brasil na Hierarquia de Clusters das Redes Comerciais por Intensidade Tecnológica}

Nos itens anteriores foram apresentados alguns indicadores de centralidade para avaliar as redes de comércio internacional e a posição do Brasil. Na técnica de cluster, o que importa são os padrões de ligações entre os vértices, apresentando, assim, as características gerais da rede e permitindo uma visão mais estrutural. Com essa técnica é possível, também, verificar a função de cada cluster dentro da rede. Com isso, tem-se que esta análise complementa a do item 3.3. Assim, a partir das estruturas das redes, divididas em quatro clusters, o objetivo deste item é avaliar o posicionamento do Brasil nessa classificação, sua função dentro de cada estrutura, verificar se houve deslocamento entre os anos de 2003 e 2012 e avaliar as características dos clusters.

A Tabela 4 refere-se a alguns indicadores e características gerais dos clusters. Tem-se o número de países que compõem cada cluster, o índice de dissimilaridade, as médias do grau de saída não ponderado e do autovetor de saída ponderado e a localização do Brasil dentro desses clusters. Quanto ao número de países, observa-se, em praticamente todos os setores e para os dois anos, um reduzido número de países no cluster 1 e uma grande quantidade de países nos demais clusters, sendo crescente quando se movimenta do cluster 2 para o cluster 3 e para o cluster 4 . Tal fato destaca que o primeiro cluster é mais concentrado, apresentando um número reduzido de países com maior poder na rede, em cada um dos setores. 


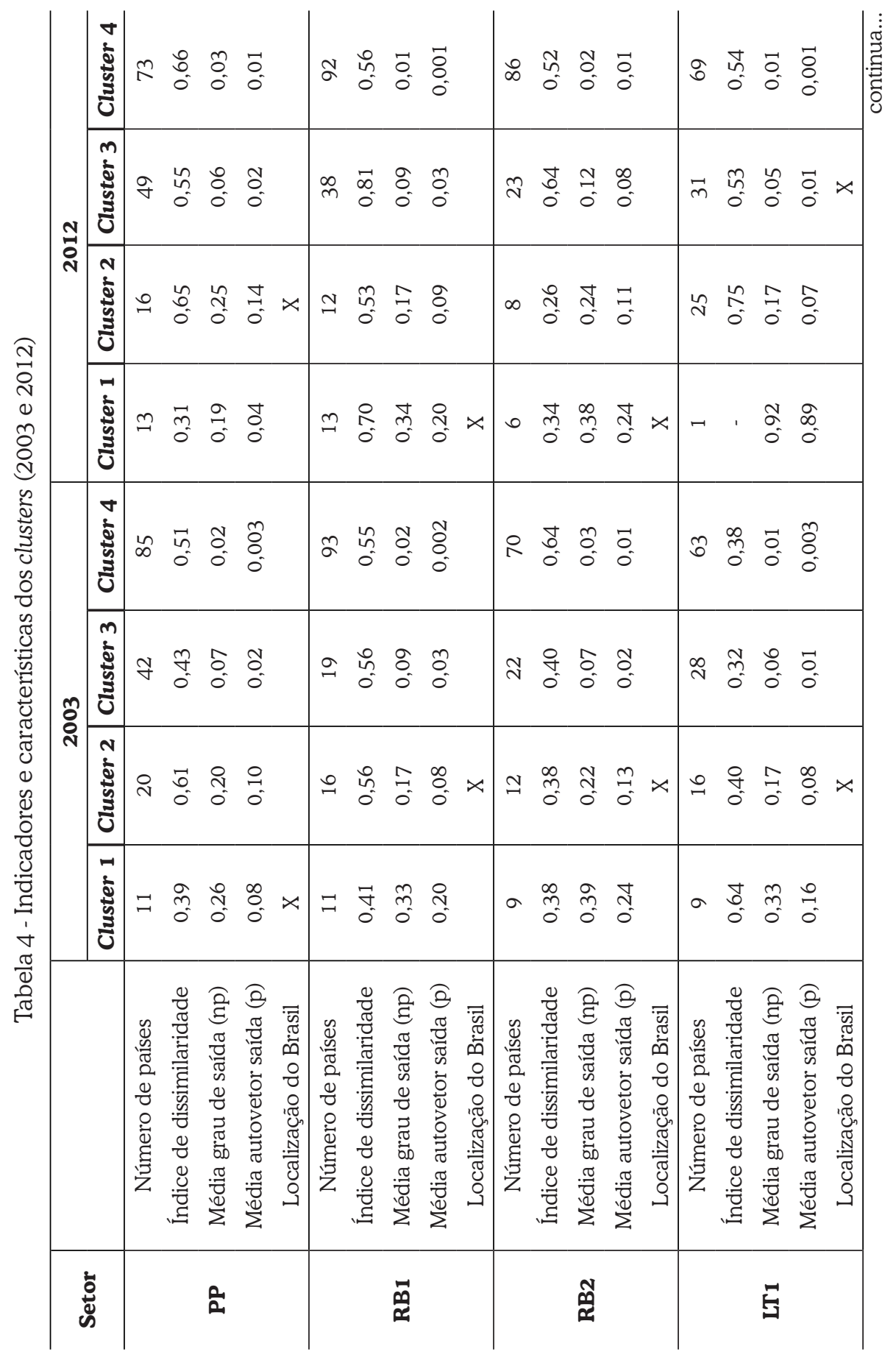




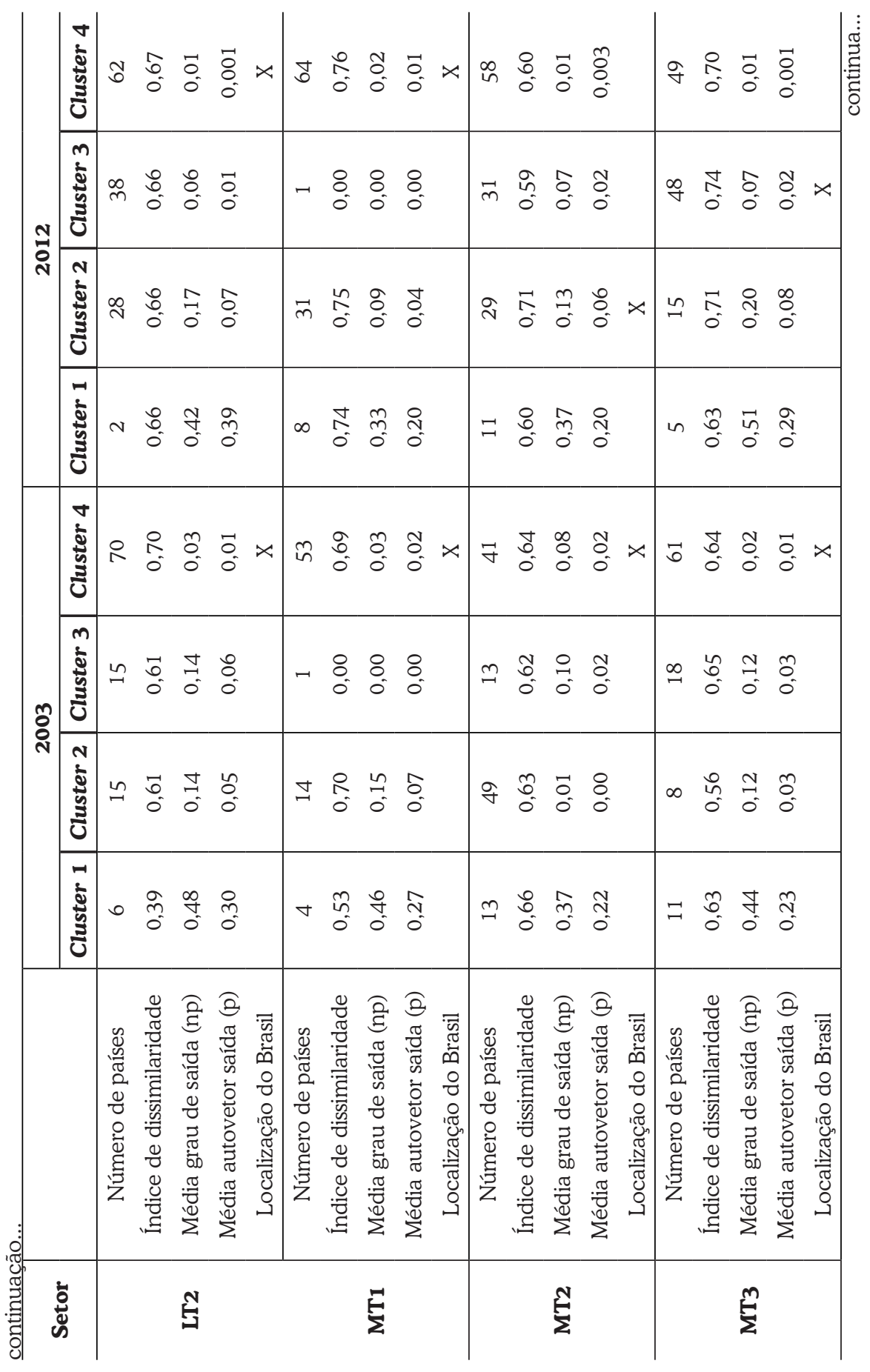




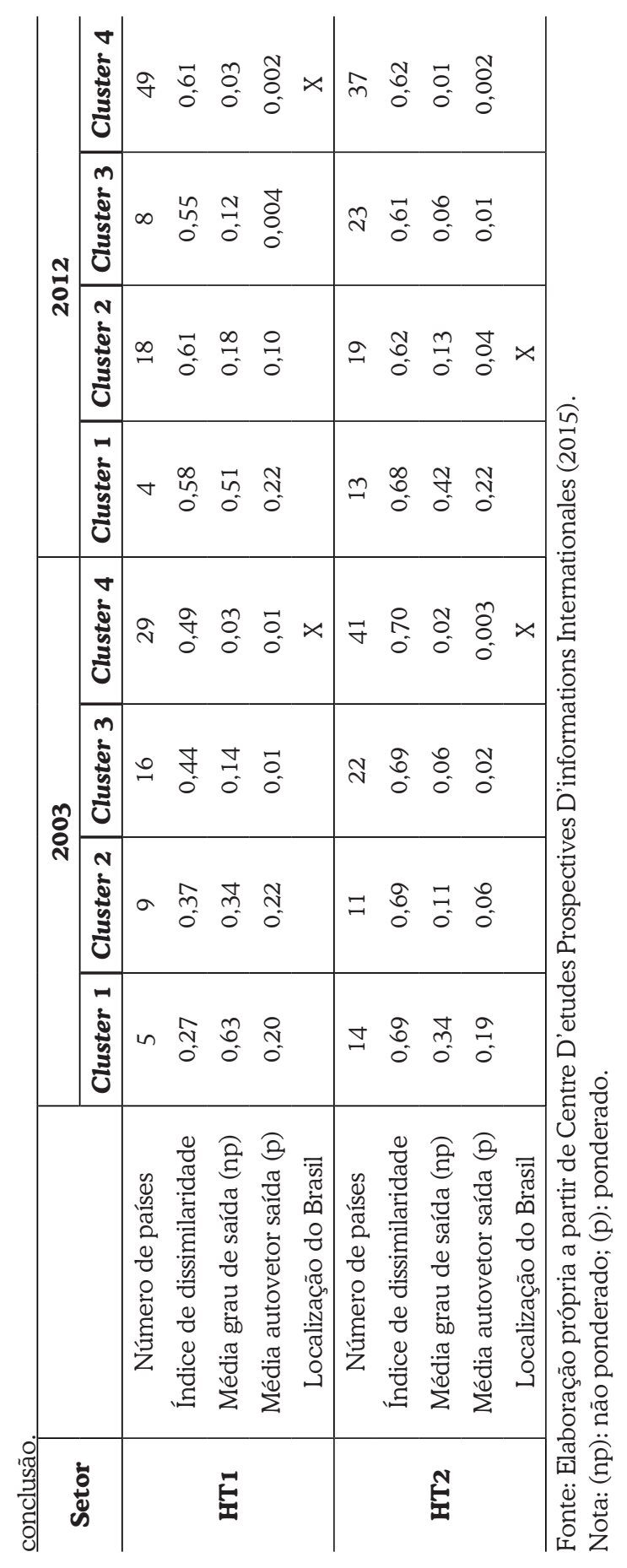


Os clusters foram divididos de acordo com a semelhança do índice de dissimilaridade dos países. Entretanto, como no comércio eles não são idênticos, dentro de um mesmo cluster existirão países dissimilares, e esse indicador apresenta, então, em cada cluster, qual é este índice entre os países que o compõem. Como se pode observar, não existe um padrão para esse indicador, já que variou de acordo com o cluster e o setor dentro do intervalo de 0,26 até 0,81 , demonstrando clusters com países mais semelhantes, até aqueles formados por países mais dissemelhantes. A maioria dos valores esteve acima de 0,50 , indicando a heterogeneidade dos países dentro do comércio internacional.

Uma medida de centralidade local utilizada foi a média do grau de saída não ponderado para cada cluster. Esses dados foram, em praticamente todos os casos, decrescentes quando se avança do cluster 1 ao 4 . Essa informação confirma que os países do cluster 1 são mais importantes em termos de sua influência local, sendo os que apresentaram maior número de saída de arcos, enquanto os países dos últimos clusters são bem menos conectados à rede.

Por fim, foi utilizada uma medida de centralidade global (média do autovetor de saída ponderado), que considera não apenas as ligações diretas, mas também as ligações indiretas de toda a rede, ponderada pelo valor exportado. Essa medida também confirmou um movimento decrescente quando se move do cluster 1 ao 4. Tal fato comprova que os países do primeiro cluster são centrais não apenas a partir de medidas de centralidade locais, mas também globais, enquanto que os países dos demais clusters, especialmente os do cluster 4, apresentam menor influência nesse indicador, estando menos conectados, além disso, conectados com vizinhos menos importantes que os países centrais.

A Tabela 5 apresenta a análise resumida da evolução da posição do Brasil, dentro desses quatro clusters, nos anos de 2003 e 2012. Em 2003, o Brasil esteve no cluster 4 (o mais periférico) em seis dos dez setores, sendo eles o LT2 e todos os de média tecnologia e de alta tecnologia. Esteve no cluster 1 apenas no setor de PP e no cluster 2, nos setores RB1, RB2 e LT1, demonstrando sua especialização em setores menos dinâmicos. Por outro lado, em 2012 observa-se um movimento de maior dispersão na classificação dos clusters, sendo que apenas três deles permaneceram no mesmo cluster que do ano de 2003 (LT2, MT1 e HT1). Os setores RB1 e RB2 passaram do cluster 2 para o 1. No setor MT3, o país movimentou-se do cluster 4 para o 3, e os maiores saltos foram para o MT2 e o HT2, nos quais o país deslocou-se do cluster 4 para o 2. Apenas no PP, o Brasil regrediu do cluster 1 para o 2 e no LT1 regrediu do cluster 2 para o 3. 
Tabela 5 - Posição do Brasil nos clusters (2003 e 2012)

\begin{tabular}{c|c|c|c|c|c|c|c|c}
\hline \multirow{2}{*}{ Setor } & \multicolumn{3}{|c|}{2003} & \multicolumn{4}{c}{$\mathbf{2 0 1 2}$} \\
\cline { 2 - 8 } & $\begin{array}{c}\text { Cluster } \\
\mathbf{1}\end{array}$ & $\begin{array}{c}\text { Cluster } \\
\mathbf{2}\end{array}$ & $\begin{array}{c}\text { Cluster } \\
\mathbf{3}\end{array}$ & $\begin{array}{c}\text { Cluster } \\
\mathbf{4}\end{array}$ & $\begin{array}{c}\text { Cluster } \\
\mathbf{1}\end{array}$ & $\begin{array}{c}\text { Cluster } \\
\mathbf{2}\end{array}$ & $\begin{array}{c}\text { Cluster } \\
\mathbf{3}\end{array}$ & $\begin{array}{c}\text { Cluster } \\
\mathbf{4}\end{array}$ \\
\hline PP & $\mathrm{X}$ & & & & & $\mathrm{X}$ & & \\
RB1 & & $\mathrm{X}$ & & & $\mathrm{X}$ & & & \\
RB2 & & $\mathrm{X}$ & & & $\mathrm{X}$ & & & \\
LT1 & & $\mathrm{X}$ & & & & & $\mathrm{X}$ & \\
LT2 & & & & $\mathrm{X}$ & & & & $\mathrm{X}$ \\
MT1 & & & & $\mathrm{X}$ & & & & $\mathrm{X}$ \\
MT2 & & & & $\mathrm{X}$ & & $\mathrm{X}$ & & \\
MT3 & & & & $\mathrm{X}$ & & & $\mathrm{X}$ & \\
HT1 & & & $\mathrm{X}$ & & & & $\mathrm{X}$ \\
HT2 & & & & $\mathrm{X}$ & & $\mathrm{X}$ & & \\
\hline
\end{tabular}

Fonte: Elaboração própria a partir de Centre D'etudes Prospectives D'informations Internationales (2015).

Esses resultados demonstram que, em termos do perfil das ligações em cada setor e dos vértices com equivalência estrutural a partir dos índices de dissimilaridade, o Brasil esteve localizado em uma posição mais periférica nas redes em praticamente todos os setores, com exceção do RB1 e do RB2, demonstrando ser um país com influência fraca, não estando nos primeiros clusters, que são os mais influentes e com maior poder dentro da rede de comércio de cada setor. Apesar disso, o país exibiu, em 2012, um movimento ascendente, se comparado ao ano de 2003, se deslocando para os clusters mais à esquerda na Tabela 5.

\section{Considerações Finais}

Este trabalho teve como motivação inicial compreender o posicionamento do Brasil na rede de comércio mundial, a partir de setores classificados por intensidade tecnológica, por meio da análise de redes, trazendo ao mesmo tempo uma metodologia ainda pouco utilizada na literatura econômica do Brasil.

A análise das informações sobre o comércio global mostrou que em geral o cenário de forte crescimento do comércio ocorrido em grande parte do período analisado neste artigo (2003-2008) resultou no aumento do número de participantes nas redes dos diferentes setores, com o aumento do número de ligações e uma tendência a aumentar o número de países com maior grau de centralidade dentro da rede, observado pelo aumento do grau médio de saída. 
Ao se analisar a inserção brasileira na rede de comércio mundial, observou-se que essa maior abertura nas redes comerciais foi aproveitada pelo Brasil basicamente pelos setores de não manufaturados (PP) e de manufaturas baseadas em recursos (RB1 e RB2), além do setor MT2. Nos demais setores, o desempenho do Brasil não pode ser considerado satisfatório, uma vez que o sentido em geral foi de piora no ranking com base nas medidas de centralidade locais e globais e de manutenção em clusters mais periféricos (com exceção do setor HT2, que pulou do cluster 4 para o 2). Além disso, é importante destacar que o desempenho foi mais negativo considerando o autovetor de saída ponderado, mostrando que o país, além de se tornar menos central, passou a ter relações com países menos centrais na rede.

Vale destacar que, comparando-se com os indicadores tradicionais, essa situação não se mostrava de maneira tão clara, uma vez que o indicador de market share mostrava ganhos em vários setores de manufaturas mais sofisticadas, e não apenas nos produtos mais intensivo no uso de recursos naturais.

Também é importante ressaltar que, se no período analisado o Brasil aproveitou as oportunidades apenas em alguns setores, perdendo posição em grupos importantes de atividades manufatureiras, no período posterior à crise, com a estagnação da demanda global e o acirramento da concorrência internacional, os desafios para as exportações brasileiras se tornaram mais complexos, seja para a manutenção do bom desempenho das exportações de atividades primárias, seja para a elevação de exportações de manufaturas mais sofisticadas. Esses desafios vão exigir um esforço redobrado, seja do setor privado, seja da política pública para que a inserção brasileira evolua de maneira mais favorável. Não faz parte do escopo deste artigo discutir a direção desses esforços, mas ressaltar que a qualidade da inserção internacional brasileira se mostrou mais frágil nos setores de produtos manufaturados.

Em certa medida, os resultados obtidos reforçam os argumentos daqueles que destacam as dificuldades crescentes da indústria brasileira, refletidas no perfil da estrutura produtiva e da pauta de exportações. Embora ajudem a caracterizar o processo, os dados analisados não tiveram como objetivo primário encontrar explicações sobre as causas desse processo. Existem várias explicações e hipóteses possíveis, passando pelos baixos investimentos em infraestrutura, as deficiências em investimento em modernização e inovação industrial/empresarial, a questão cambial, bem como a discussão recente das cadeias globais de valor e a inserção do Brasil de maneira expressiva nessas cadeias. Novos estudos podem ser efetuados, utilizando os indicadores de redes de comércio para testar essas hipóteses com metodologias econométricas apropriadas.

As informações analisadas neste estudo indicam que a utilização do instrumental de redes complexas permite ter informações adicionais que não são direta- 
mente reveladas pelos indicadores tradicionais de comércio. Pode-se dizer, portanto, que existe uma agenda de pesquisa importante que pode ser mais desenvolvida e detalhada em trabalhos futuros a partir da aplicação dessa metodologia.

\section{Referências}

BAIR, J. Frontiers of commodity chain analisys. Stamford: Stanford University Press. 2008.

BALDWIN, R. Global supply chains: why they emerged, why they matter, and where they are going. Geneva: Centre for Economic Policy Research, 2012. (Working Paper, n. DP9103). Disponível em: <http://papers.ssrn.com/sol3/papers.cfm?abstract_id=2153484>. Acesso em: 05 fev. 2016.

BARIGOZZI, M.; FAGIOLO, G.; GARLASCHELLI, D. Multinetwork of international trade: a commodity-specific analysis. Phisic Review E, v. 81, n. 4, não paginado, 2010.

BATAGELJ, V.; MRVAR, A. Pajek - Program for Large Network Analysis. Disponível em: <http://vlado.fmf.uni-lj.si/pub/networks/pajek/>. Acesso em: 04 jun. 2015.

BENEDICTIS, L. et al. Network analysis of world trade using the BACI-CEPII dataset. 2013. Disponível em: < http://www.cepii.fr/PDF_PUB/wp/2013/wp2013-24.pdf>. Acesso em: 03 dez. 2014.

BRESSER-PEREIRA, L. C. A taxa de câmbio no centro da teoria do desenvolvimento. Estudos Avançados, v. 26, n. 75, p. 7-28, 2012.

. The Dutch disease and its neutralization: a Ricardian approach. Revista de Economia Polítca, v. 28, n. 1, p. 47-71, jan./mar. 2008.

CENTRE D'ETUDES PROSPECTIVES D'INFORMATIONS INTERNATIONALES. Base Pour L'analyse Du Commerce International. Disponível em: < http://www.cepii.fr/CEPII/en/bdd_ modele/presentation.asp?id=1>. Acesso em: 10 jan. 2015.

DUEÑAS, M.; FAGIOLO, G. Modeling the international-trade network: a gravity approach. Journal of Economic Interaction and Coordination, v. 8, n. 1, p. 155-178, 2013.

ELMS, D. K.; LOW, P. Global value chains in a changing world. Genebra: WTO Publications, 2013.

FAGIOLO, G.; REYES, J.; SCHIAVO, S. World-trade web: topological properties, dynamics, and evolution. Physical Review E, v.79, Mar. 2009.

FEIJÓ, C. A.; LAMONICA, M. T. Importancia del sector industrial para el desarrollo de la economía brasileña. Revista de la Cepal, n. 107, p. 115-136, 2012.

HAUSMANN, R. et al. The atlas of economic complexity. 2011. Disponível em: < http://atlas. cid.harvard.edu/media/atlas/pdf/HarvardMIT_AtlasOfEconomicComplexity.pdf $>$. Acesso em: 28 jan. 2016.

HAUSMANN, R.; HIDALGO, C. The building blocks of economic complexity. Proceedings of National Academy os Science USA, v. 106, n. 26, p. 1-42, 2009. 
HERTEL, T. et al. Global Trade Analysis: modeling and applications. 1997. Disponível em: $<$ https://www.gtap.agecon.purdue.edu/resources/res_display.asp?RecordID $=4840>$. Acesso em: 05 fev. 2016.

HIRATUKA, C.; SARTI, F. Transformações na estrutura produtiva global, desindustrialização e desenvolvimento industrial no Brasil: uma contribuição ao debate. Campinas: IE/Unicamp, jun. 2015. (Texto para discussão, n. 255).

JACKSON, M. Social and economic networks. Princeton: Princeton University Press, 2010.

JENKINS, R. Measuring the competitive threat from china for other southern exporters. The World Economy, v. 31, n. 10, p. 1351-1366, 2008.

LALL, S. The technological structure and performance of developing countries manufactured exports, 1985-1998. Oxford Development Studies, v. 28, n. 3, p. 337-369, 2000.

LAUTENSCHLAGER, A.; CATERMOL, F. Características estruturais da rede de comércio internacional. Revista Brasileira de Comércio Exterior, v. 28, n. 118, p. 90-96, 2014.

MAHUTGA, M. C. The persistence of structural inequality? a network analysis of international trade, 1965-2000. Social Forces, v. 84, n. 4, p. 1863-1889, jun. 2006.

MEDEIROS, C. A. Padrões de investimento, mudança institucional e transformação estrutural na economia chinesa. In: CENTRO DE GESTẪO E ESTUDOS ESTRATÉGICOS. Padrões de Desenvolvimento Econômico: América Latina, Ásia e Rússia. v. 2. Brasília, DF: CGEE, 2013.

MORCEIRO, P. C. Desindustrialização na economia brasileira no período 2000-2011: abordagens e indicadores. 2012. 219 f. Dissertação (Mestrado em Economia) - Universidade Estadual Paulista, Faculdade de Ciências e Letras, Araraquara, 2012.

NOOY W.; MRVAR A.; BATAGELJ, V. Exploratory social network analysis with pajek, structural analysis in the social sciences. Cambridge: Cambridge University Press, 2005.

OREIRO, J. L.; FEIJÓ, C. A. Desindustrialização: conceituação, causas, efeitos e o caso brasileiro. Revista de Economia Política, v. 30, n. 2, p. 219-232, 2010.

REYES, J.; SCHIAVO, S.; FAGIOLO, G. Using complex network to asses the evolution of economic integration: the case of East Asia and Latin America. Piza, Italy: Santanna School of Advanced Studies, 2007. (LEM Working Paper Series, 2007/25).

SCOTT, J. Social network analysis: a handbook. Nova York: Sage publications, 2000.

SERRANO, A.; BOGUÑ́, M.; VESPIGNANI, A. Patterns of dominant flows in the world trade web. Journal of Economic Interaction and Coordination, v. 2, n. 2, p.111-124. 2007.

SILVA, S. T.; DATHEIN, R. Formação, expansão e internacionalização de grandes grupos empresariais chineses como estratégia de estado. Revista da Sociedade Brasileira de Economia Política, n. 37, p. 67-95, 2014.

SMITH; D. A.; WHITE, D. R. Structure and dynamics of the global economy: network analysis of international trade 1965-1980. Social Forces, v. 70, n. 4, p. 857-893, 1992. 
SNYDER, D.; KICK, E. L. Structural position in the world system and economic growth, 1955-1970: a multiple-network analysis of transnational interactions. American Journal of Sociology, v. 84, n. 5, p. 1096-1126, 1979.

TACCHELLA, A. et al. Economic complexity: conceptual grounding of a new metrics for global competitiveness. Journal of Economic Dynamics and Control, v. 37, n. 8, p. 1683-1691, 2013.

VERGNHANINI, R. O debate sobre a mudança estrutural da economia brasileira nos anos 2000. 2013. 123 f. Dissertação (Mestrado em Economia Política Internacional) - Programa de Pós-Graduação em Economia Política Internacional, Instituto de Economia, Universidade Federal do Rio de Janeiro, Rio de Janeiro, 2013.

VERÍSSIMO, M. P.; XAVIER, C. L.; VIEIRA, F. V. V. Taxa de câmbio e preços de commodities: uma investigação sobre a hipótese da doença holandesa no Brasil. Revista Economia, v. 13, n. 1. 2012.

WALLERSTEIN, I. The rise and future demise of the World Capitalims System: concepts for comparative analysis. Comparative Studies in Society and History, v. 16, n. 4, p. 387-415, 1974.

ZACCARIA, A. et al. How the taxonomy of products drives the economic development of countries. Plos One, v. 9, n. 12, 2014. 


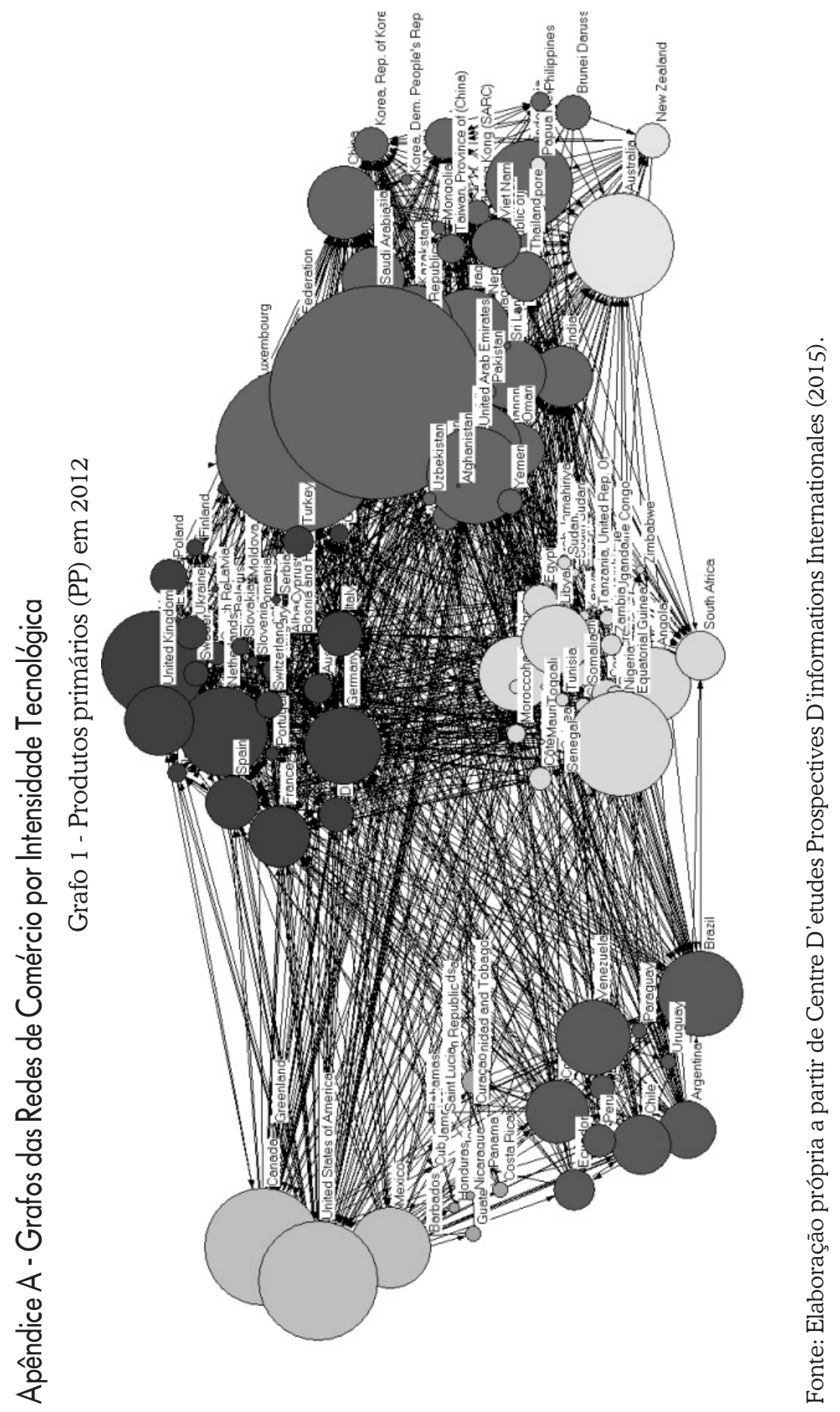




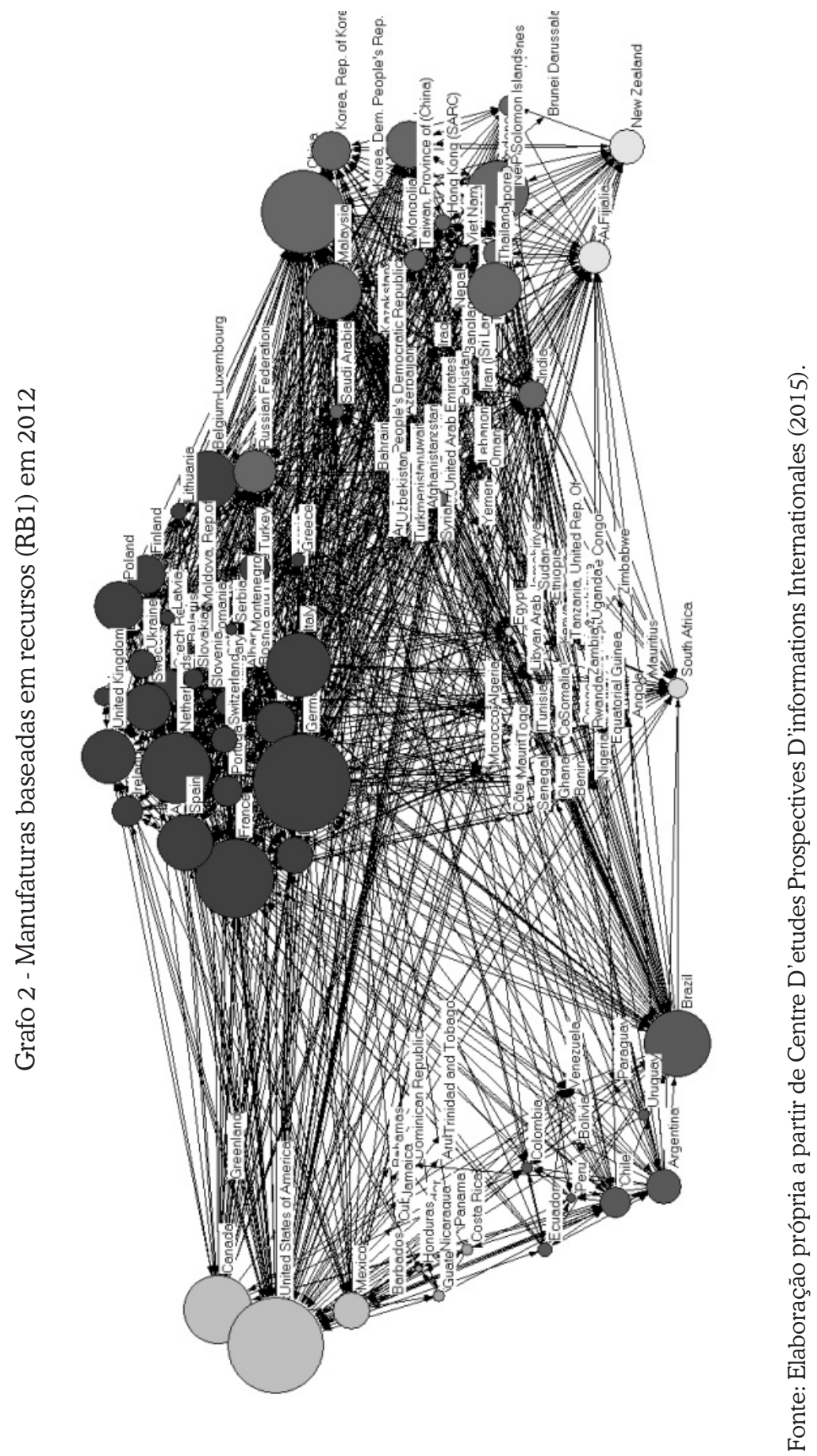

YAMANE, D. F. et al. Avaliação da Inserção do Brasil no Comércio Internacional... 


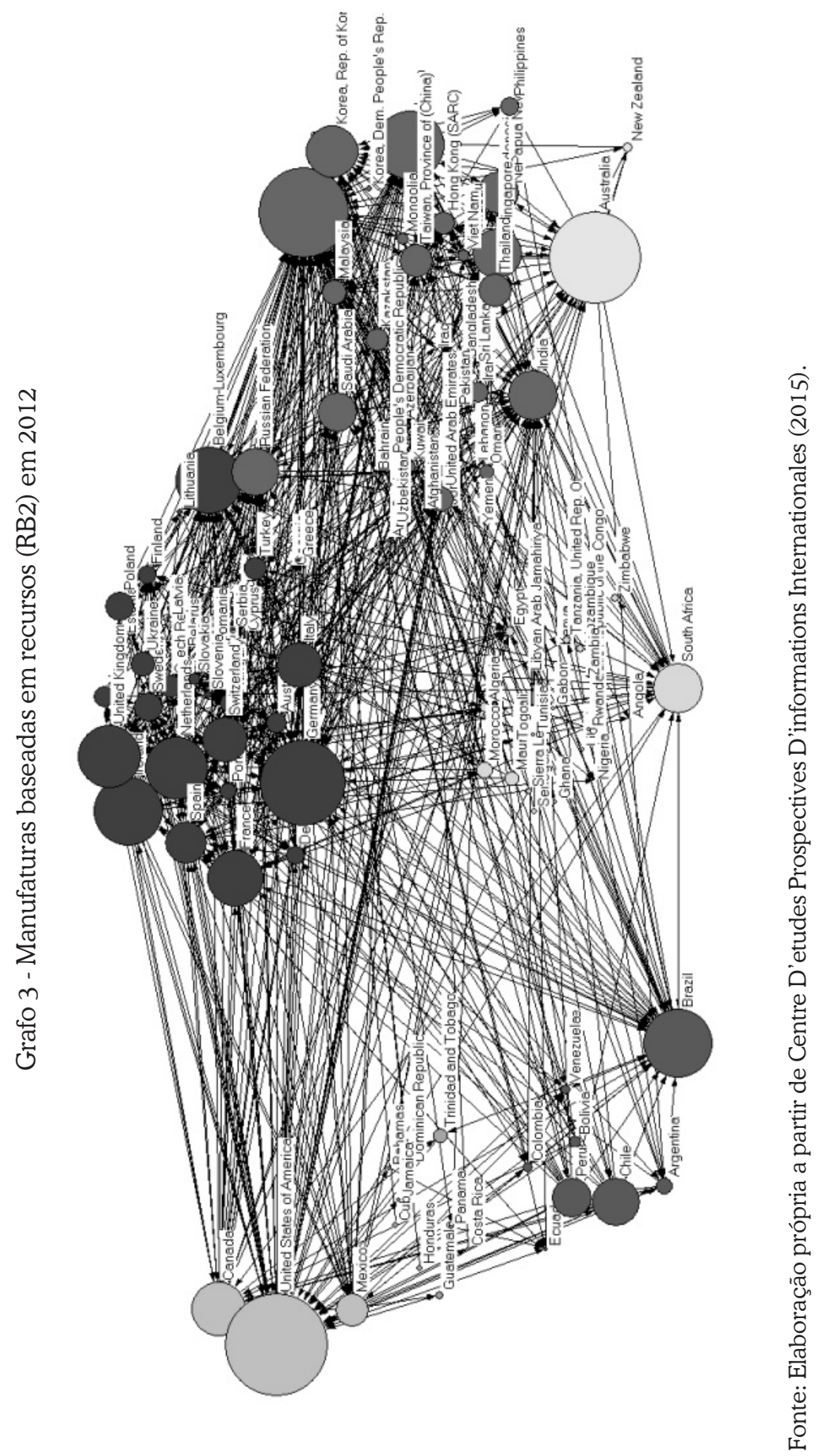




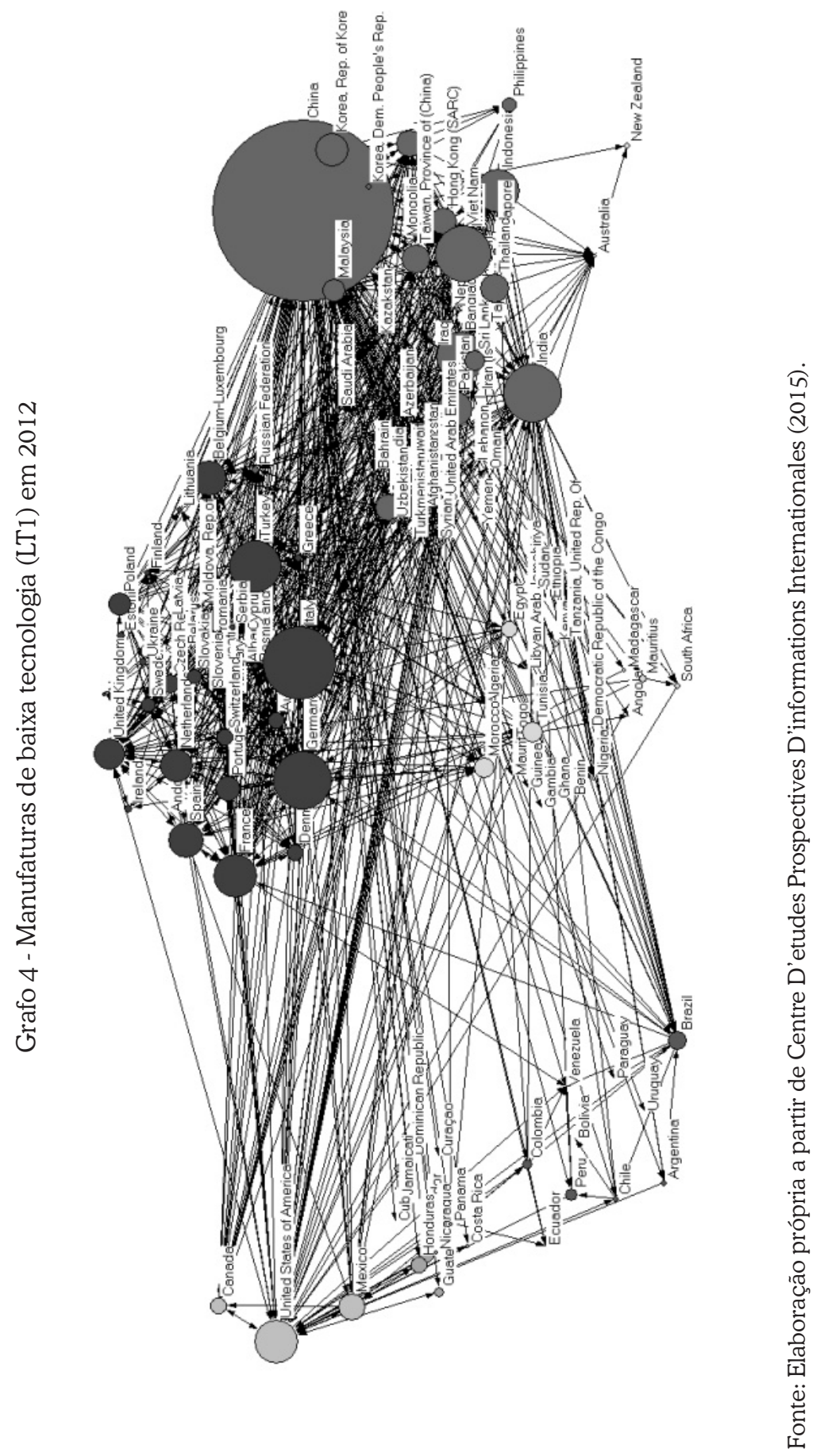

YAMANE, D. F. et al. Avaliação da Inserção do Brasil no Comércio Internacional... 


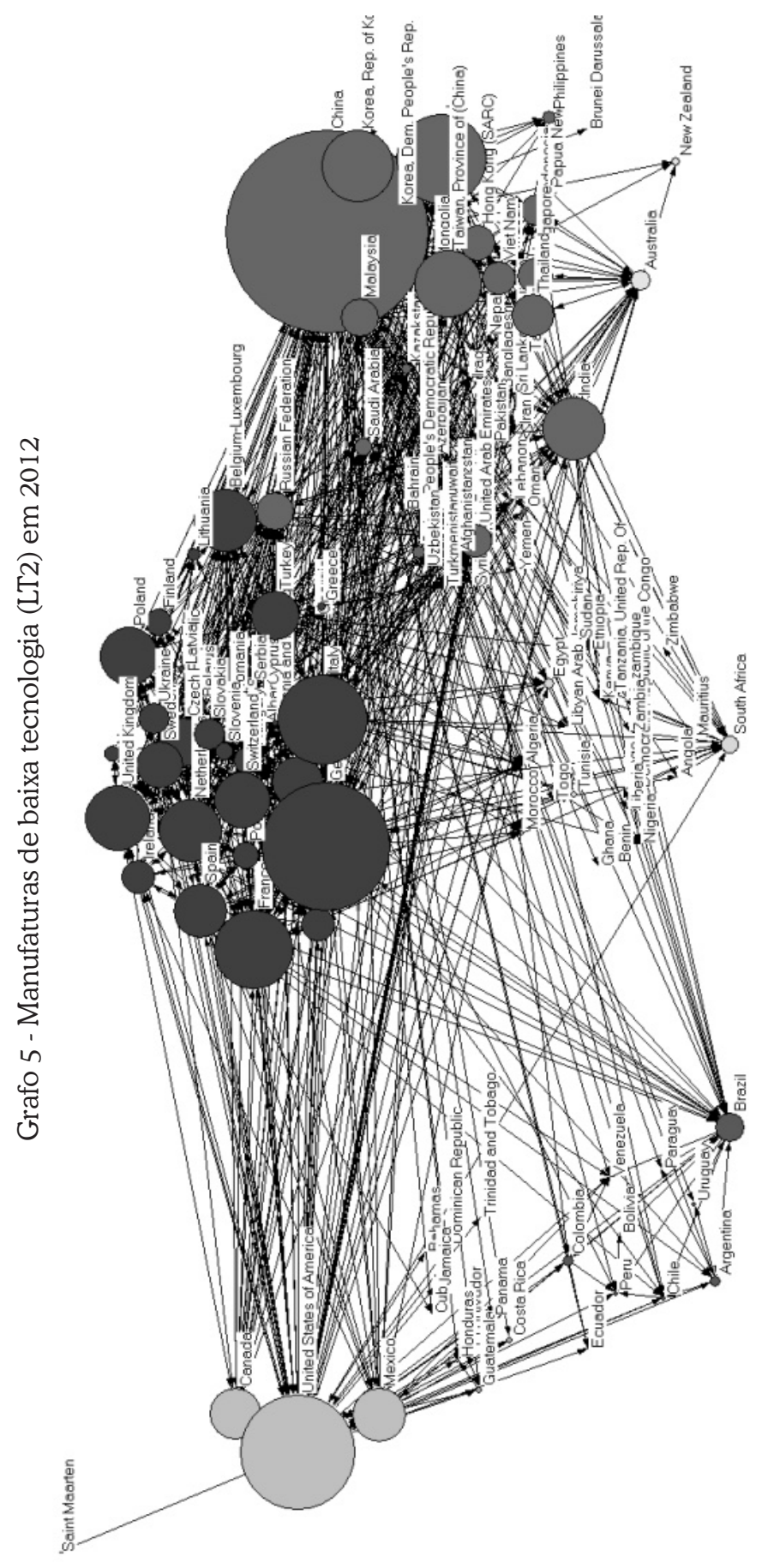

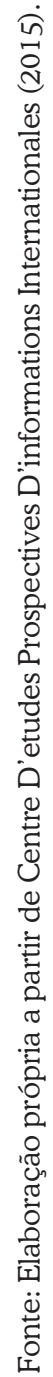




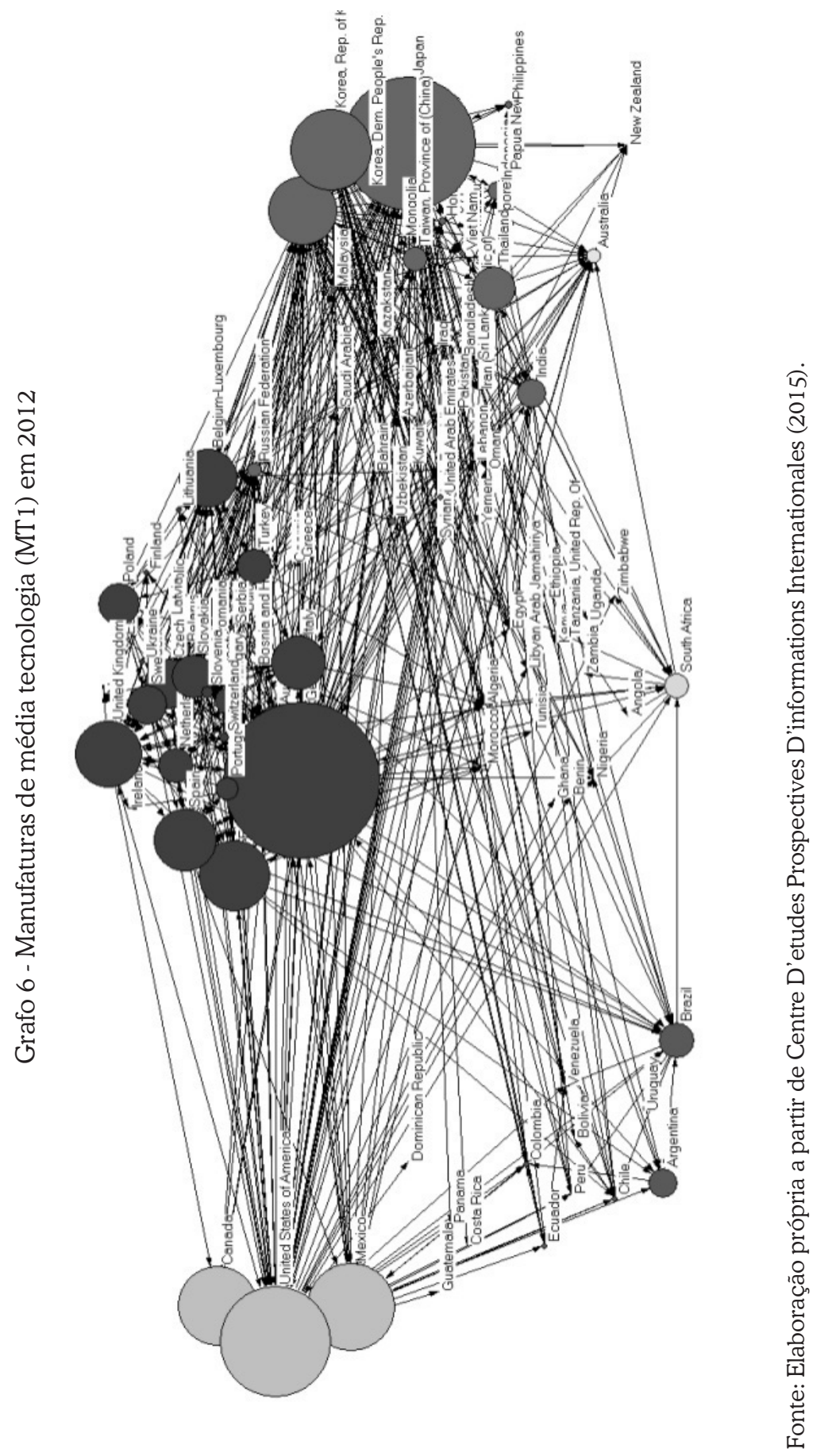

YAMANE, D. F. et al. Avaliação da Inserção do Brasil no Comércio Internacional... 


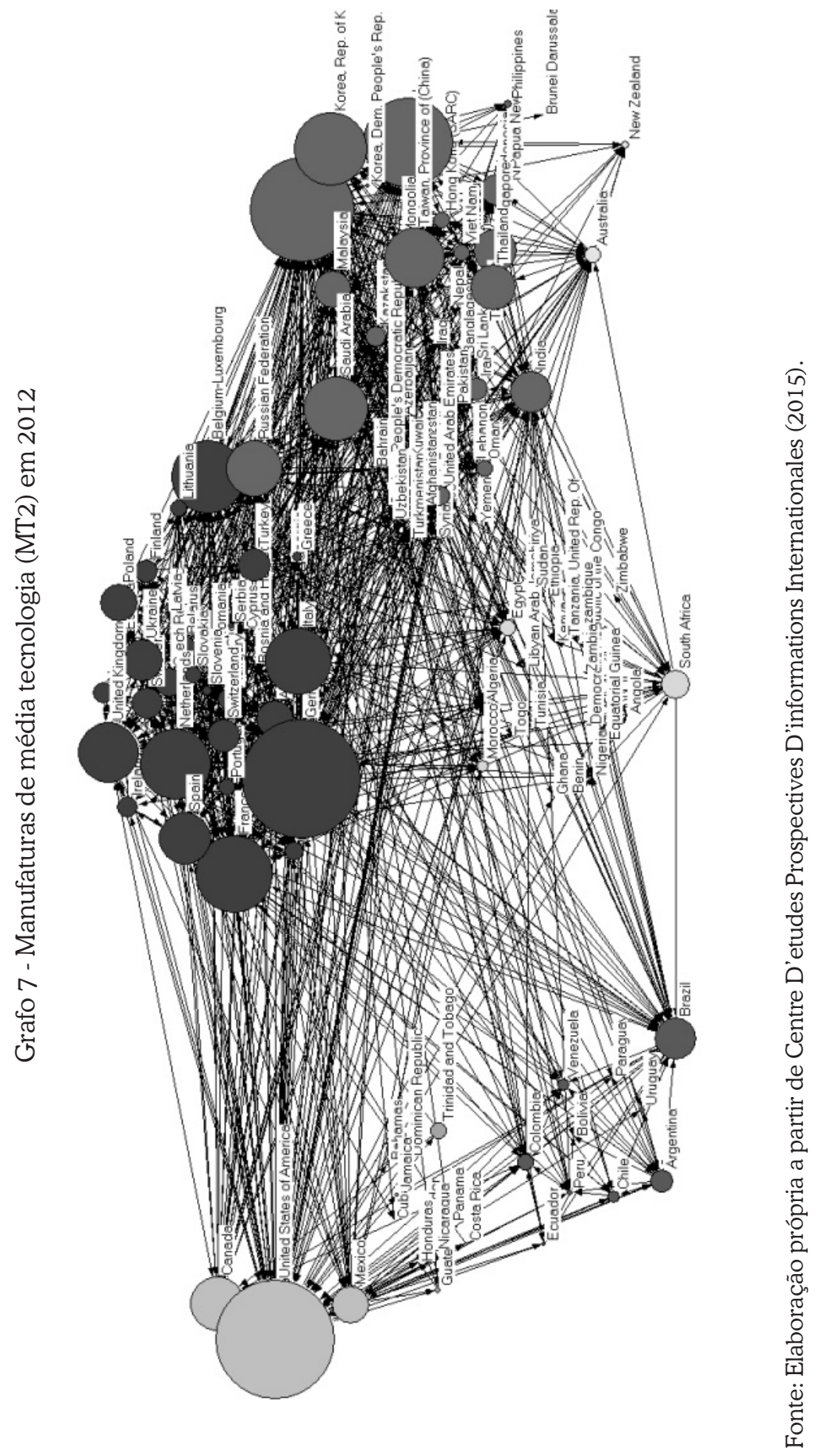




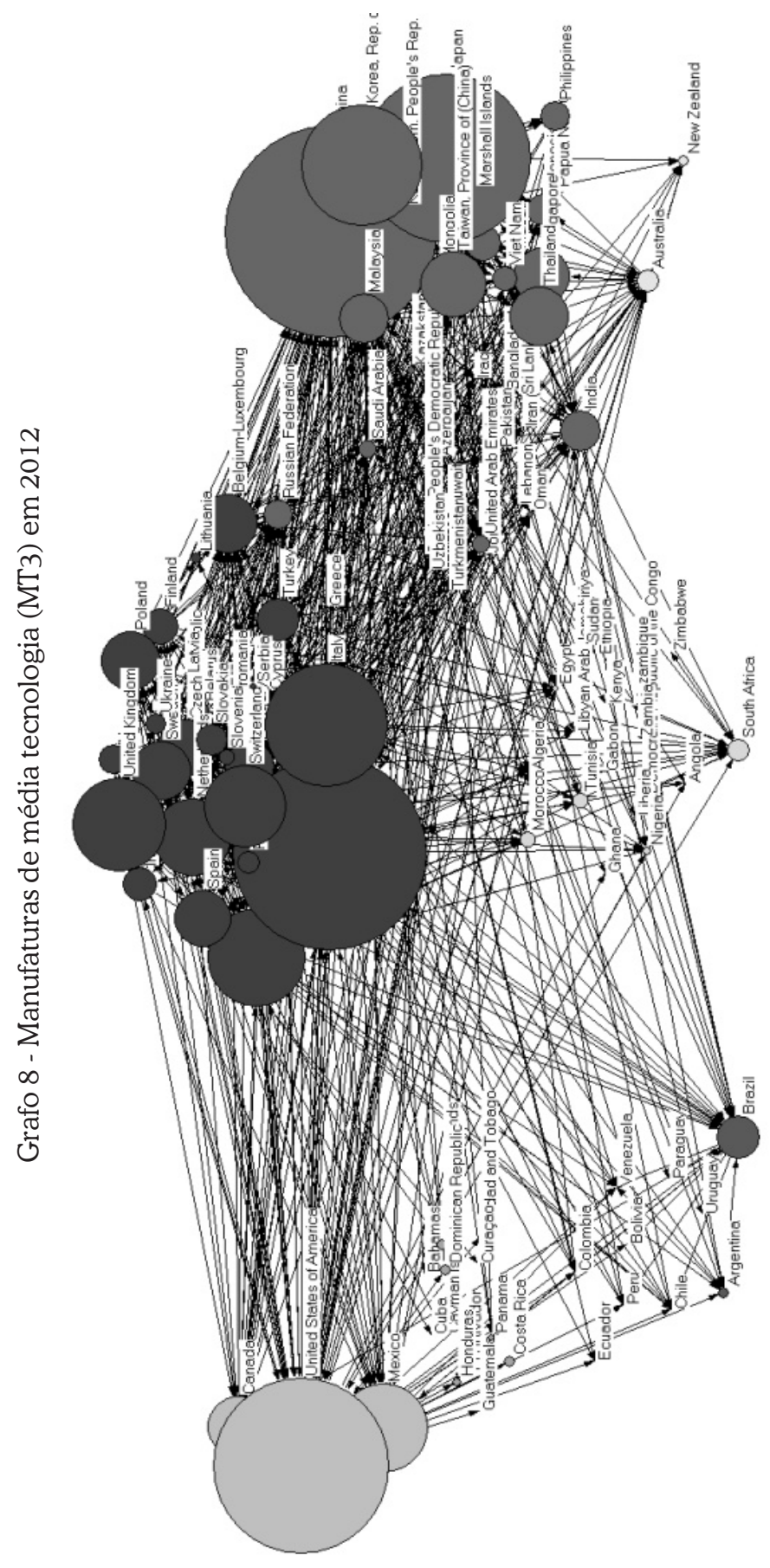

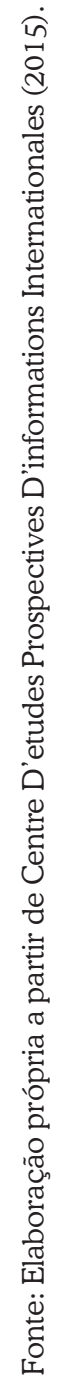

YAMANE, D. F. et al. Avaliação da Inserção do Brasil no Comércio Internacional... 


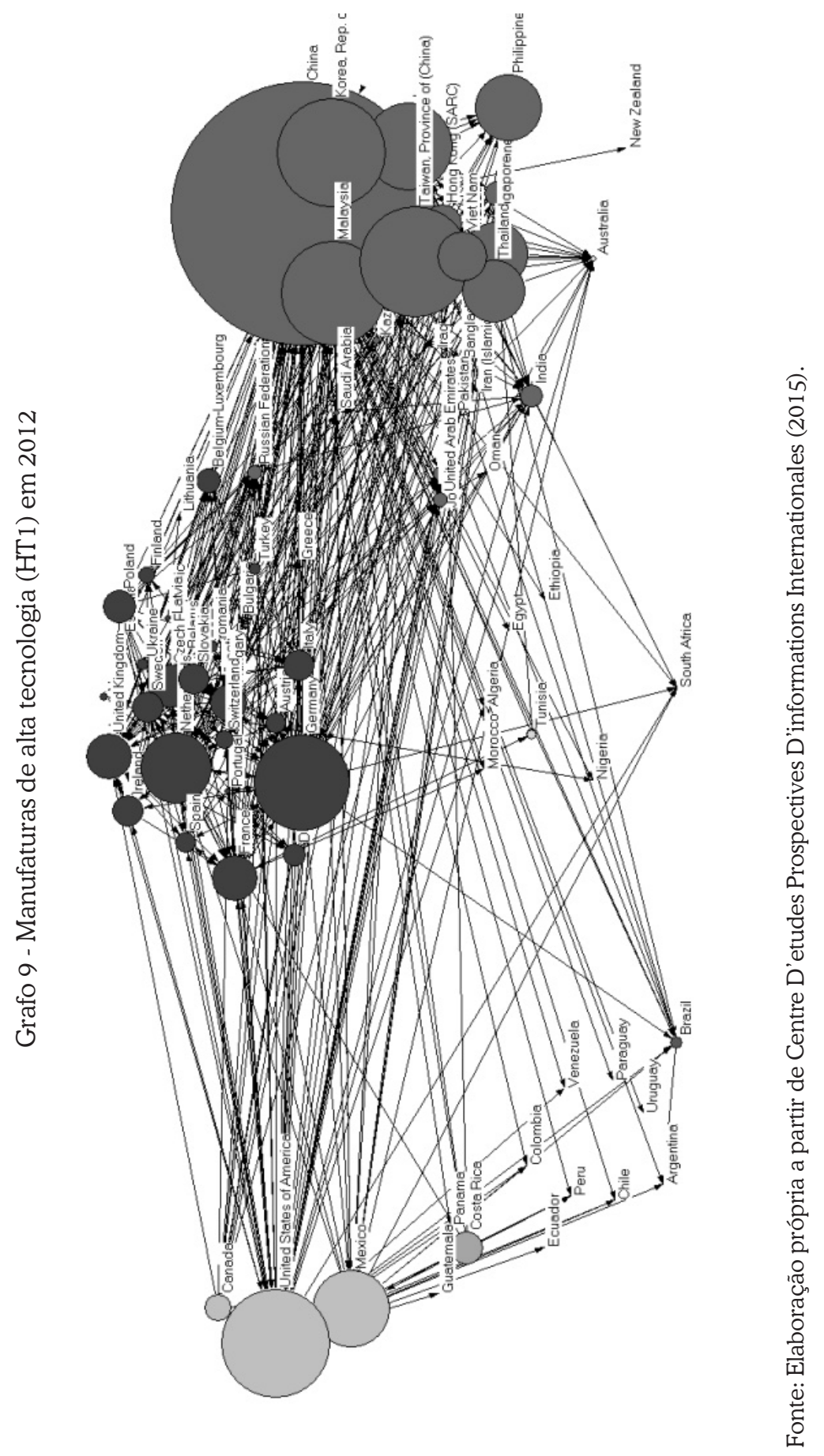




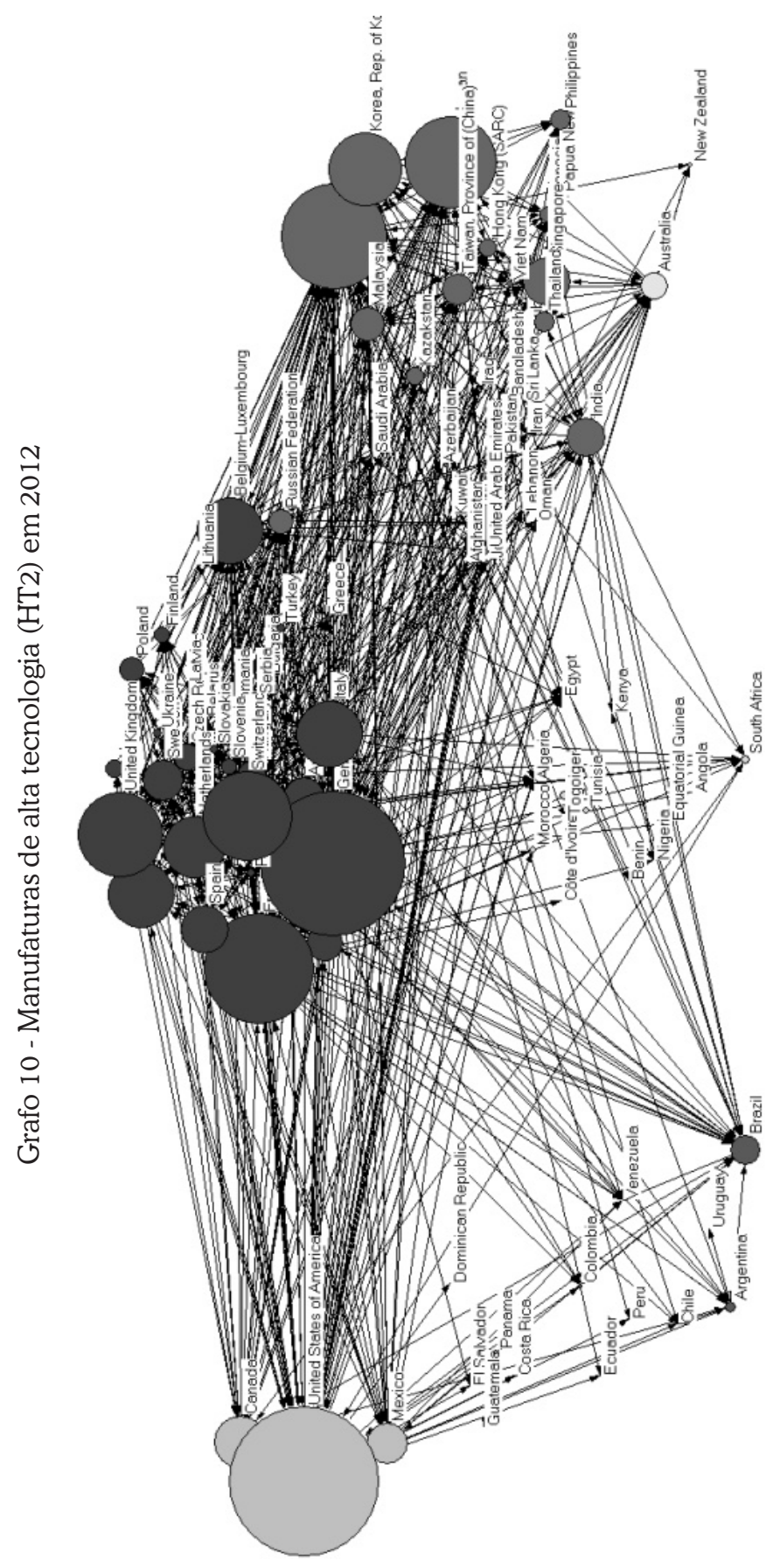

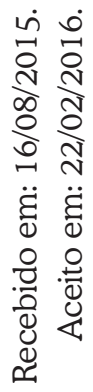

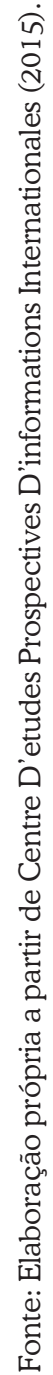

